Review Article

\title{
Advances in Human Biology: Combining Genetics and Molecular Biophysics to Pave the Way for Personalized Diagnostics and Medicine
}

\author{
Emil Alexov \\ Computational Biophysics and Bioinformatics, Department of Physics, Clemson University, Clemson, SC 29634, USA \\ Correspondence should be addressed to Emil Alexov; ealexov@clemson.edu
}

Received 29 January 2014; Revised 23 April 2014; Accepted 17 June 2014; Published 7 July 2014

Academic Editor: Yinan Wei

Copyright (c) 2014 Emil Alexov. This is an open access article distributed under the Creative Commons Attribution License, which permits unrestricted use, distribution, and reproduction in any medium, provided the original work is properly cited.

Advances in several biology-oriented initiatives such as genome sequencing and structural genomics, along with the progress made through traditional biological and biochemical research, have opened up a unique opportunity to better understand the molecular effects of human diseases. Human DNA can vary significantly from person to person and determines an individual's physical characteristics and their susceptibility to diseases. Armed with an individual's DNA sequence, researchers and physicians can check for defects known to be associated with certain diseases by utilizing various databases. However, for unclassified DNA mutations or in order to reveal molecular mechanism behind the effects, the mutations have to be mapped onto the corresponding networks and macromolecular structures and then analyzed to reveal their effect on the wild type properties of biological processes involved. Predicting the effect of DNA mutations on individual's health is typically referred to as personalized or companion diagnostics. Furthermore, once the molecular mechanism of the mutations is revealed, the patient should be given drugs which are the most appropriate for the individual genome, referred to as pharmacogenomics. Altogether, the shift in focus in medicine towards more genomic-oriented practices is the foundation of personalized medicine. The progress made in these rapidly developing fields is outlined.

\section{Introduction}

The human body is a delicate, self-regulating machine which can respond to its surroundings and internal needs. Such selfregulation involves various processes ranging from processes on atomic and molecular level to processes occurring in organs and tissues. Despite such tremendous complexity, somehow all humans, broadly speaking, are quite similar. However, slight differences in DNA can lead to a multitude of other physical differences. Some of these differences are harmless such as eye and hair color [1], race [2], and skin color $[3,4]$, while other differences may be disease-associated (see special J. Mol. Biol. issue [5]). The differences among individuals and their susceptibility to diseases are not only due to the single nucleoside polymorphisms (SNPs), but also due to the fact that different individuals have different copy numbers variations (CNVs) for various genes [6-9]. As pointed out by Haraksingh and Snyder [6], the CNVs are perhaps even more important for the humans than the SNPs, a statement supported by other researchers [10-13]. In the end, from the viewpoint of personalized diagnostics and medicine, the most important task is to differentiate between disease-causing and harmless DNA differences. At the same time, from the viewpoint of Biology and Biophysics, one wants to reveal the molecular mechanisms arising from all of the DNA differences in order to understand the biological processes taking place in human body. Figure 1 schematically illustrates harmless and disease-causing DNA differences, where different individuals carrying different DNA mutations are different in either their physical appearance (tall and short) or a predisposition to diseases (healthy and sick).

This paper outlines the progress made in human genome sequencing and detection of DNA differences as the necessary first step for personalized diagnostics. It is followed by reviewing the advances made in methods for discriminating disease-causing and harmless mutations. Simply predicting 


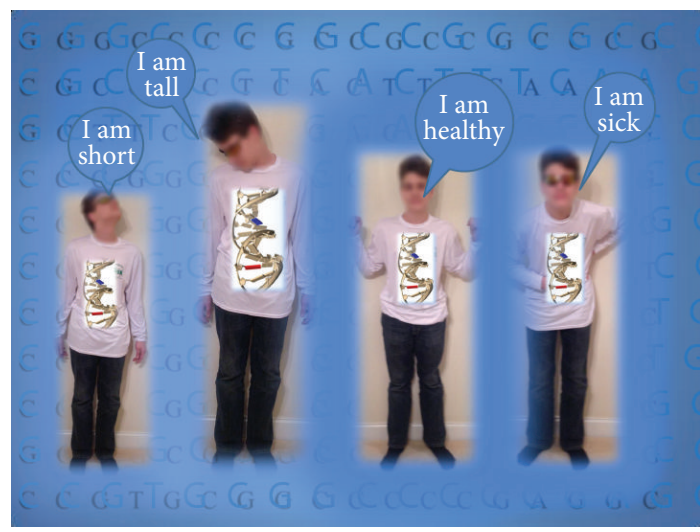

FIGURE 1: Illustration of human harmless variation (short and tall man) and human variation-causing disease (healthy and sick man).

that a given DNA defect is disease-causing is not enough for an effective personalized treatment, and thus the paper proceeds to review the approaches and techniques for predicting the molecular mechanism of disease-causing mutations for the needs of personalized diagnostics, pharmacogenomics, and personalized medicine.

\section{Progress Made in Genome Sequencing and Database Development}

Personalized diagnostics and medicine cannot be developed without access to the genomic data of the patient, which, in turn, requires inexpensive and fast methods for individual genome sequencing $[14,15]$. The progress made in developing methods and techniques for detecting genetic variations was recently outlined in several works [16-18]. These techniques are rapidly evolving and various companies promised or already achieved the goal of being able to sequence an entire genome for a price tag of $\$ 1,000$ within a day $[19,20]$. However, despite the success of whole-genome sequencing, it is now understood that the analysis of genomic variations with respect to disease susceptibility is a much more complicated process and requires significant efforts [21]. If the sequencing is attempting to target a particular disease-in the simplest case a monogenic disease-then the analysis of the variations within a particular gene is typically a quite doable task. However, if the question is broader and if one wants to investigate the whole genome of the currently healthy individual with the goal of predicting future disease-causing defects, the problem becomes enormously complicated. One ends up with thousands or millions of variants spread over many different genes and noncoding regions of the genome. Identifying which of these variants might be associated with disease predisposition is not a trivial task. To assist in solving this difficult challenge, the 1,000 genomes project was founded. This project is aimed at revealing human variations within the entire genome by using the whole-genome sequencing of the DNA of 1,000 volunteers from different backgrounds $[22,23]$. This is intended to provide information on the most frequently observed DNA variations, and the data is now available on the internet [24]. One can assume that genetic variations identified within the 1,000 genomes project are not necessarily disease-causing, since the volunteers are healthy individuals. However, it should also be noted that some diseases have very late onsets and may not be manifested at this stage in the individual's life.

The interpretation of the individual's genomic data has another difficult component, CNVs. Although important and frequently associated with diseases, CNVs cannot be easily used to reveal the molecular effect of a disease. One can speculate that a larger number of copies of a given gene will automatically result in a greater expression level of this particular protein and that this is the cause of the disease. However, this mechanism will not be discussed in this paper, because understanding the effect requires a detailed knowledge of the biological reactions associated with the target protein and how the change in the concentration level of individual macromolecules will affect the cellular function.

The progress in this fast growing field prompted development of databases on various levels such as disease-oriented databases to databases storing all of the known human DNA variations (Table 1). The creation of such databases serves two very important purposes: providing benchmarks to test in silico predictions and providing template cases or patterns for the detection of disease-causing mutation(s). Perhaps the most popular disease-oriented database is McKusick's Online Mendelian Inheritance in Man (OMIM) database $[25,26]$, which is a manually curated database of human genes and genetic disorders including genetic phenotypes [26]. Since its establishment in early 1960s, many researchers have contributed to various aspects of the OMIM database such as developing extra features resulting in OMIM derivatives as PhenOMIM (for phenotypic comparison) [27], OMiR (to reveal associations between OMIM diseases and microRNAs) [28], CSI-OMIM (assisting clinical synopsis search in OMIM) [29], CGMIM (for text-mining of cancer genes) [30], and many other applications. On the other end of the spectrum is the dbSNP [31, 32] database at National Center for Biotechnology Information (NCBI). As of December 2013, it contains more than 140 million single nucleotide polymorphisms (SNPs), and the rate of new submissions is constantly increasing. In terms of distinguishing between disease-causing and harmless mutations, typically, one would create a pseudo-harmless database by taking out all of the entries from dbSNP that are listed in OMIM [33]. The remaining SNPs can be considered neutral or harmless, although exceptions to this rule will always be found. It should be noted that many other databases exist as well, some that focus on a particular disease $[34,35]$, others that focus on nonsynonymous SNPs $[36,37]$ or regulatory SNPs [38], or one that focuses on a particular family of genes $[39,40]$.

Although the goal of this paper is not to provide comprehensive review of all existing human variation databases, the HapMap [41] project and database cannot be omitted. The goal of the HapMap project is to develop a map of the common patterns of human DNA sequence variation. It is intended to be used to provide information about genes and patterns causing natural differences among individuals 


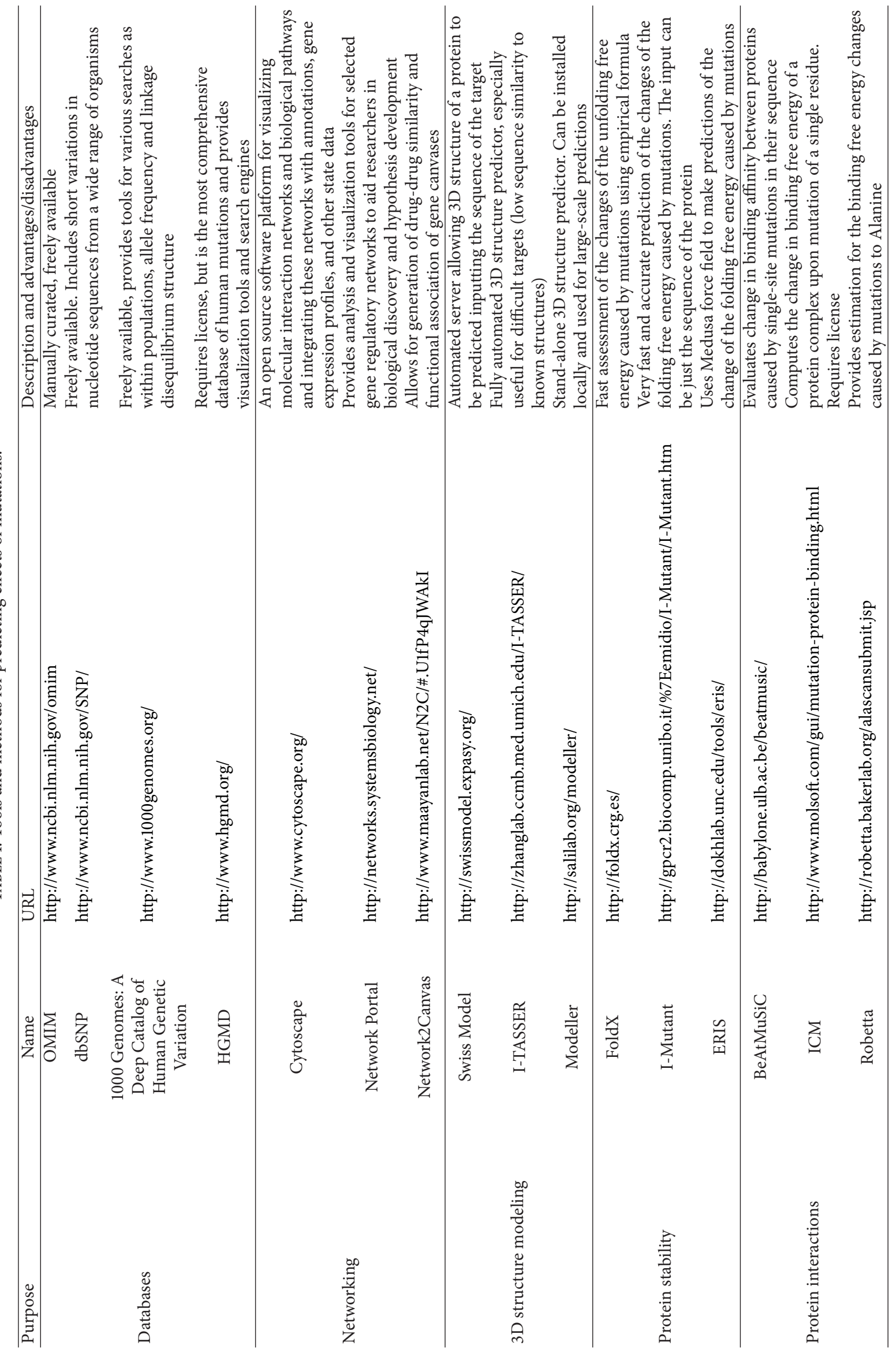




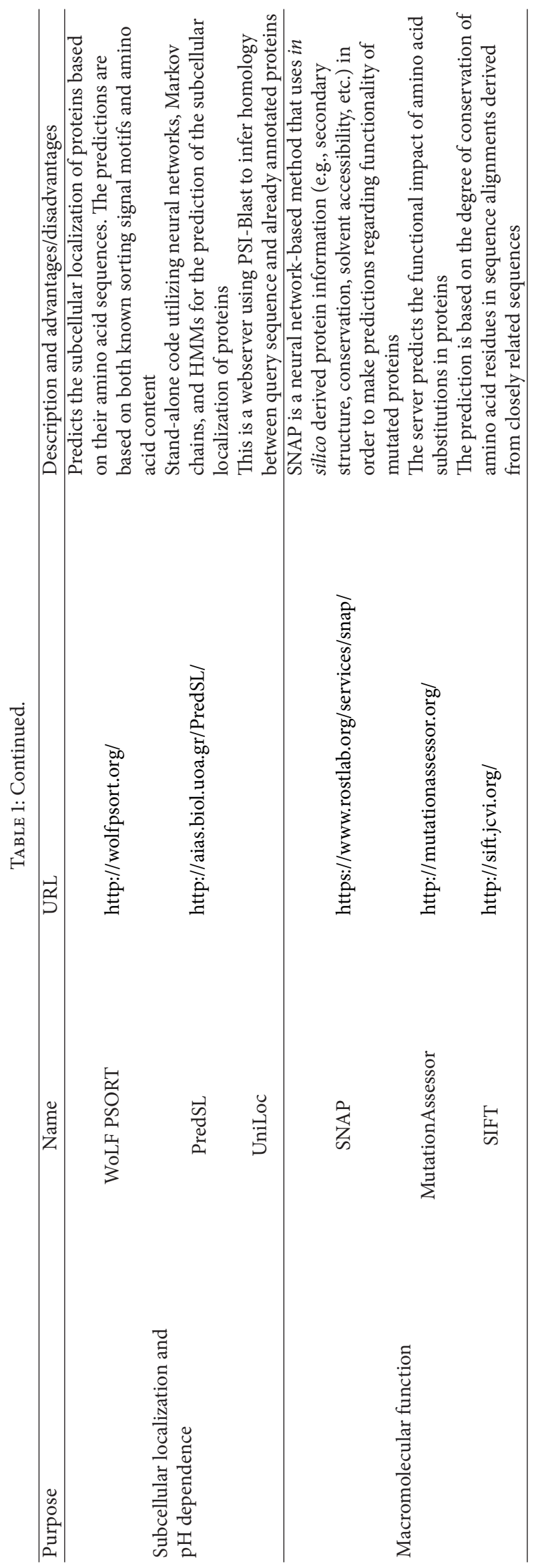


[42-45] as well as the predisposition to diseases [46, 47], responses to drugs [48], and cell phenotype [49].

\section{Progress Made in Developing Methods for Revealing the Molecular Mechanisms of Disease-Causing Missense Mutations}

The progress made in developing approaches to reveal the molecular mechanism of disease-causing mutations is outlined in several reviews [50-52]. Here, we briefly summarize the major approaches and developments, focusing on those which allow not only for classification of mutations as disease-causing or harmless, but also for providing information on what the dominant molecular mechanism behind the mutation is (Table 1). The focus of this paper is utilizing structural information to deliver predictions; however, in principle, one can make reasonably specific predictions about the effect of mutations on the protein interaction network using sequence information only. Because of this, the discussion below begins with a networking analysis and other associated approaches and then outlines the progress made in the structural space, and finally it demonstrates how the structural information can be used to reveal the details of the effects of a mutation.

3.1. Progress Made in Networking. Every macromolecule participates in various interactions resulting in a complex network in the cell. Understanding the effects of mutations requires evaluating the corresponding effect on the entire network as discussed recently [53]. Such an analysis is crucial for understanding complex diseases, that is, diseases caused by mutations in several genes. The observation that the same disease can be caused by different mutations in different genes leads to the conclusion that the phenotype is caused by multiple modifications at the molecular level, perhaps by disrupting the same network components. Because of this, complex diseases are frequently referred to as diseases of pathways $[53,54]$. Understanding the effect of genetic differences on the corresponding networks requires generating the network representation and mapping the differences onto it. Typically, this is done by generating a graph on which the genes are placed at the nodes (vertices) and the interactions are represented as the links (edges) between the nodes. Perhaps the most widely used resource for the visualization of such networks is Cytoscape [55-58], although many alternative solutions do exist [59-62]. The main challenge is to identify or predict which genetic mutations affect which interaction, in other words, how to best map the mutations onto the edges of the graph. In some limited cases, associating a particular mutation with a particular interaction can be done by extracting data from the literature, analyzing the $3 \mathrm{D}$ structure of the corresponding complex, performing docking and then analyzing the structure of the docked complex, or predicting residues that participate in the interaction (correlated mutation sites) [63, 64]. This is still one of the main bottlenecks for large-scale modeling. Even if the genetic defects can be successfully associated with the edges of the network and assuming that these mutations simply remove the corresponding edge (a very simplified assumption, since more frequently the mutations weaken [33, 65] or strengthen [66] molecular interactions, not completely abolishing them), the next question is to predict the effect of edge removal on the disease phenotype. Only if all these questions are properly addressed can a prediction be made as to what the molecular mechanism of given disease (utilizing networking approach) is and, in turn, be able to point out which molecular interactions are affected and how this affects the cellular function.

Another challenge is that human interactome is far from complete and there are many missing interactions which have not been discovered yet $[67,68]$. In addition, there are also many interactions detected by high-throughput methods which may not be real physical interactions taking place in the cell $[69,70]$. Combined with dynamic nature of interactome [71, 72], it is clear that significant work needs to be done to better understand how mutations affect the network and, in turn, how the changes in the interactome, local or global, are associated with the wild type function of the cell. In particular, it is important to take into account the redundancy in the human interactome to prioritize plausible genes involved in a disease [73].

3.2. Progress Made in Structural Genomic Consortiums and 3D Structure Predictions. Structural genomic consortiums are intended to promote development of methods, tools, and approaches to deliver the 3D structures of novel proteins [74-77]. Depending on the overall goal, the focus varies from determining the $3 \mathrm{D}$ structure of proteins found in the human genome, proteins of medical importance, or proteins from other genomes. In the process of selecting targets whose structures are to be experimentally determined, either by the means of X-ray crystallography or by NMR, researchers frequently pick up genes which represent large class of proteins with no $3 \mathrm{D}$ structure available $[76,78]$. Such an approach is intended to result in an equally populated conformational space and to provide homologous 3D structures for a maximum number of protein sequences. With the ever-growing Protein Data Bank (PDB) [79, 80], which as of December 2013 has 96,596 experimentally determined macromolecular structures (including proteins, RNA, and DNA), the investigations focusing on a particular gene (protein) are frequently able to find either the 3D structure of the wild type protein or the structure of a close homolog in the PDB, with an unfortunate lack of membrane and scaffolding proteins. If the 3D structure of the target protein is not available, one should build a model using the most appropriate homolog(s).

There are many different approaches for 3D structure predictions, varying from homology-based to first-principlebased approaches [81-87]. While all these methods have strengths and weaknesses, from point of view of delivering high quality 3D models, including models for large proteins, the homology-based approaches are far superior to the rest. As summarized by Moult, there is a significant improvement in methods utilizing template-based approaches which can be seen comparing the results of tenth Critical Assessment of 
Structure Prediction (CASP) experiments [88]. The resulting 3D models of individual macromolecules, especially if based on highly homologous template(s), are of a higher quality that allows for meaningful structural analysis $[89,90]$ and even for carrying out various energy calculations [91, 92].

At the same time, since practically every macromolecule is involved in various interactions including interactions with other macromolecules [93, 94], it is equally important to reveal the interacting partners and the structure of the corresponding protein complexes. Several databases summarize and provide details about such interactions [95-98], including the changes to the binding affinity caused by mutations [99]. While a significant amount of thermodynamics data exists, very few structures of macromolecular complexes are available (as compared with monomeric macromolecules) and therefore the structures have to be predicted in most cases [100-103]. The 3D structures are typically modeled via either homology-based methods [104-108] or docking [109112]. The performance of these approaches is tested in the community-wide experiment on the Critical Assessment of Predicted Interactions (CAPRI) [113], and it was concluded that the performance of docking and scoring methods has remained quite robust but challenges still exist [113-116]. Either way, one needs either experimentally determined 3D structure or a high quality model of the corresponding macromolecular complex in order to carry out structural analysis and evaluate the various energy components $[33,65]$.

The above considerations are with respect to the wild type macromolecules, which from genetics perspective typically are referred to as dominant allele. It is quite unlikely to expect that the $3 \mathrm{D}$ structures of the minor alleles or rare/unique mutant macromolecules and the corresponding complexes will be experimentally determined independently. Instead, the mutant structures are built from the wild type structures by either side chain replacement [117-121] or insertion/deletion of a structural segment [122-124] and further structural relaxation [33, 65, 125-128].

\subsection{Progress Made in Understanding the Details of Disease- Causing Mechanisms Utilizing Structural Information.} Revealing the effect(s) of genetics differences on the wild type cellular function can be done either experimentally or in silico. It is quite unlikely that experimental approach will be applied for each individual case, due to the fact that experiments are time-consuming and may require a significant investment. Due to this, in silico approaches must be utilized. Since the goal is to reveal the details of the effect, not just the effect itself, one needs structural information. To reiterate once more, it should be clarified that, for example, a prediction that a given mutation destabilizes the corresponding protein, which can be done without structural information, is not sufficient for understanding the details of the effect. Instead, one has to be able to predict what the structural changes caused by the mutation(s) are and how these changes can be reduced or eliminated by small molecule stabilizers. Below, we review the progress made in several major directions such as predicting the effect on (Section 3.3.1) protein integrity [50], (Section 3.3.2) protein interactions [129], and (Section 3.3.3) protein subcellular localization and $\mathrm{pH}$-dependent properties. We purposely focus on these directions because, in principle, these effects can be fixed with external stimuli, such as small molecules. Interested readers should be referred to several other review papers exploring different effects $[5,51,52]$. In the end, it is important to recognize that the most successful predictions are expected to be done addressing the effects above and simultaneously taking into account the specificity of the function of the corresponding target. However, frequently, the precise function or the details are unknown and have to be predicted. The necessity of revealing macromolecular function in terms of understanding the disease mechanism and the progress made in this direction are discussed in Section 3.3.4.

3.3.1. The Effect on Protein Integrity. The effect on protein integrity is typically assessed via predicting the changes of the folding free energy, conformational dynamics, and hydrogen bond networks [50]. With this in mind, one of the main obstacles in predicting if a given mutation is deleterious is the ambiguity of how large the deviation from native property of a given protein should be in order to be disease-causing. For example, some proteins are very stable having a large folding free energy and small changes caused by mutation(s) may not be deleterious. At the other end of the spectrum are intrinsically unstable proteins with a folding free energy of a few $\mathrm{kcal} / \mathrm{mol}$; for them, almost any change in the folding free energy is expected to be deleterious. In order to avoid this particular problem with respect to protein folding free energy, an approach was developed to mutate all native residues to the rest of ninety amino acids and to construct the mutability landscape to guide the selection of deleterious mutations [130]. Such an approach allows the decision to be made based on the energy landscape of each particular protein. Another investigation introduced quantities such as "tolerance" and "mutability" for mutation sites to indicate if the site itself can tolerate substitutions and also to detect if these substitutions are amino acid specific [131]. Various approaches exist to predict the changes of protein stability due to mutations [132-137]. The performance of such selected methods, including resources which do not utilize structural information, was reviewed in recent reports and it was indicated that the ability of the methods to deliver accurate predictions is quite limited [138] and better tools are required [139].

The above considerations focus mostly on protein folding free energy changes caused by mutations; however, of equal importance are the effects of the mutations on macromolecular dynamics and the details of hydrogen bonding, especially in the neighborhood of the active site. Alteration of the hydrogen bond network within the active site or other structural regions important for the biological reaction is typically always deleterious $[126,128,140,141]$. Changes in macromolecular dynamics, especially for proteins whose function requires conformational changes, can cause diseases [66, 142-144]. These changes in the hydrogen bond pattern and conformational flexibility are typically predicted via standard 
molecular dynamics or energy minimization simulations. Provided that the mutations do not cause drastic structural alterations, the existing molecular dynamics packages are quite successful in revealing these changes [50].

3.3.2. The Effect on Protein Interactions. Essential components of cellular machinery are protein-protein interactions. Any missense mutations, especially those at the protein binding sites, can affect the affinity and interaction rates as discussed in a recent review [129]. Currently, there are several structure-based approaches to predict the changes of the binding free energy due to missense mutations $[132,145-$ 150]. These methods utilize the experimentally delivered 3D structure of the corresponding protein-protein complex. If the structure of the complex is not available, the alternative is to dock the monomeric proteins, to predict the $3 \mathrm{D}$ structure of the complex, and then to evaluate the effect of the mutation on the binding affinity. The performance of such approaches to predict structural changes and changes in the binding affinity caused by mutations is reviewed in recent article [151] and it is concluded that significant improvement is needed to improve the performance.

Despite the fact that the existing methods are not particularly accurate to predict the exact changes of the binding free energy due to mutation, as can be seen from benchmarking tests against various databases of experimental data points $[95,97,99]$, the predictions still can be used to evaluate the trend of the changes without being too concerned about the magnitude of the changes $[33,65,66,131]$. In addition, the structures of the corresponding complexes, either experimentally available or modeled in silico, can be used for structural analysis to predict the effect of mutations $[152,153]$. With this in mind, of particular interest is the inferred biomolecular interaction server (IBIS) at NIH/NCBI $[154,155]$. Thus, one can use structural information to make a reasonable prediction about whether the mutation will be tolerated or not, that is, if the mutation will have drastic effect on the protein's wild type interactions.

\subsubsection{The Effect on Subcellular Localization and $p H$ Depen-} dence. Macromolecules carry out their function by sensing various environments and, particularly in the cell, are localized in different subcellular compartments or are trafficked across different compartments. Each subcellular compartment as well as different body organs has a specific characteristic $\mathrm{pH}$ as compiled in several reports [156-160]. Macromolecules must be delivered to the correct compartment in order to function properly and any mutation that changes the signal peptide will have a deleterious effect on the function [161-163]. In addition, any mutation that alters the $\mathrm{pH}$-dependent properties, either the $\mathrm{pH}$ dependence of protein stability $[156,157]$ or the protein-protein interactions $[156,157,160,164,165]$ (including the changes of protonation states $[166,167])$, may be deleterious. Such an analysis is not easy to do since the decision about the effect must be taken into account along with the subcellular or organ characteristic $\mathrm{pH}$ where the wild type protein is supposed to function, which is information that is not typically available.
If the characteristic $\mathrm{pH}$ is known and the structures of the corresponding macromolecules and their complexes are available, then there are many in silico tools to predict the effect of mutations on the $\mathrm{pH}$ dependence of folding and interactions as recently reviewed [168]. Some of them predict the conformational changes and the changes of hydrogen bond patterns as well, providing additional information to be analyzed. The performance of the existing methods of $\mathrm{pKa}$ calculations is increasing the accuracy to much higher levels by reducing the overall error to less than $1 \mathrm{kcal} / \mathrm{mol}$ [169]; this range is frequently sufficient for analyzing the effect of mutations.

In terms of predicting the effect of mutations on the properties of the signaling peptide, one can assess the effect using various databases and servers of signaling peptides [170-172]. Although considerations must be made about the accessibility of the signaling peptide from the water phase, in most cases just the sequence information is needed to make the prediction.

3.3.4. The Macromolecular Function and Effects of Mutations. In the above paragraph, the macromolecular function was frequently mentioned and it was repeatedly said that the effects of mutations should be evaluated in terms of their effect on macromolecular function. However, there are still macromolecules in the human genome which are not annotated [173], even for those whose 3D structures were experimentally determined via Structural Genomics Initiatives, so termed orphan proteins $[174,175]$. It is infeasible that these functionalities will be experimentally studied, and these proteins and RNAs should be annotated computationally $[173,176-179]$. Having in mind the importance of developing in silico tools for functional annotation, recently, the first large-scale community-based critical assessment of protein function annotation (CAFA) experiment has begun [180]. The results from the first round are quite encouraging in terms of the fact that standard sequence-based approaches such as Blast are capable of detecting sequence similarity and thus of inferring function [181], but it was indicated that there is a need for improvement of currently available approaches [180]. The main challenges include the definition of protein function and evaluation of predictions to be independent of the dataset [181].

In conclusion of this section, it should be clarified that indeed the currently available methods for structure analysis and predictions, energy calculations, hydrogen bond network modeling, assessment of conformational dynamics, and functional annotations are not perfect and need improvement. Still, if applied together to study any particular macromolecule and its associated mutations, it typically delivers meaningful results as indicated by comparing with the experimental data of the relevant case studies $[66,92,126-$ $128,131,182,183]$.

\section{Personalized Diagnostics}

Armed with the abovementioned tools, the ultimate goal is to be able to detect disease-causing DNA defects even before 


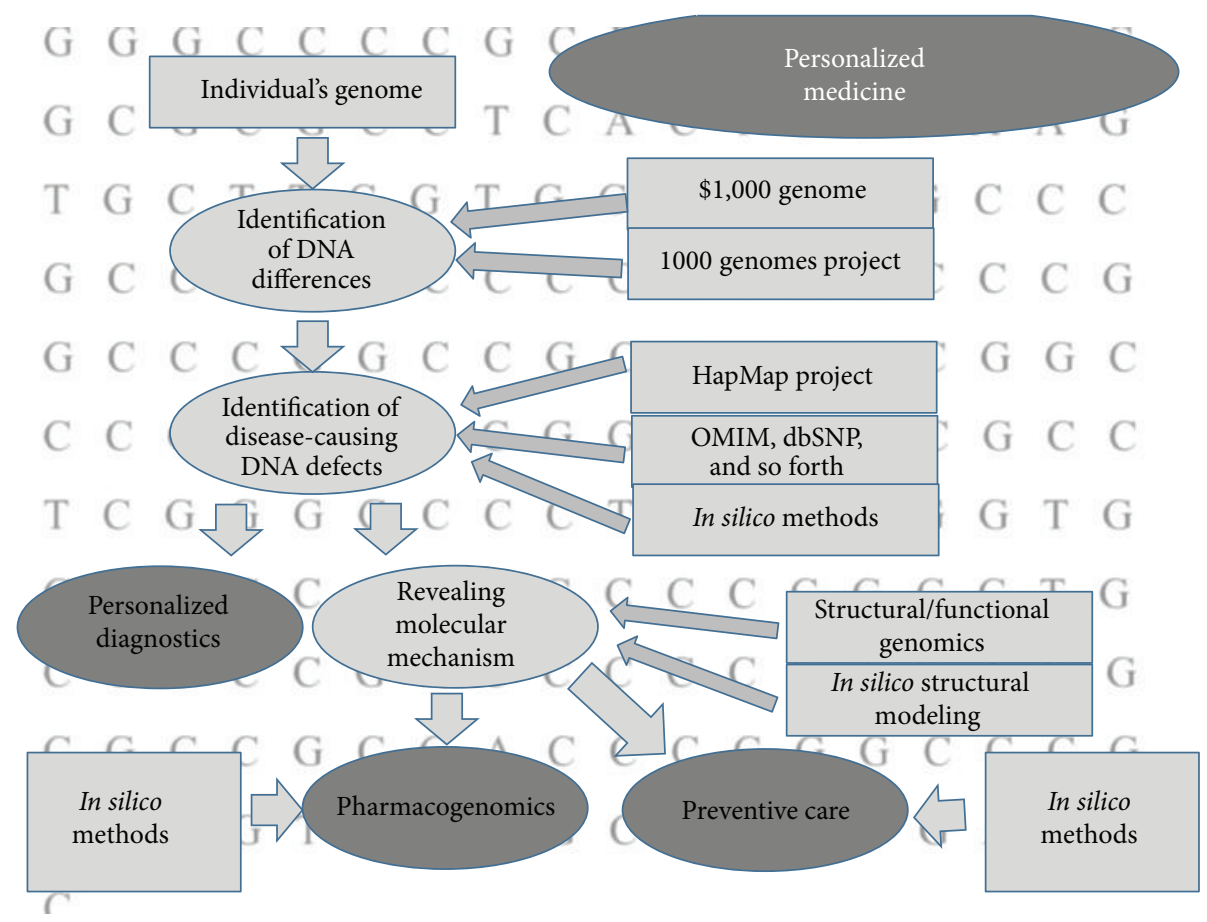

FIGURE 2: Flowchart representing the basic components behind personalized genome-oriented medicine.

the disease is clinically manifested [184, 185]; however, it is equally important to pinpoint the disease-causing effect [66, 92, 127, 128, 183] (Figure 2). The last case of investigations is essential for building a library of DNA defects associated with particular diseases, that is, database of genotypes causing particular disease [186]. The increasing number and size of such databases is essential for fast and precise diagnostics, since the only information required is the individual's genome. Once the individual genome is mapped onto the database of the diseases' genotypes, the prediction of the disease predisposal can be done instantly. Perhaps the best approach is to collect DNA samples from all individuals, especially individuals in their early life, make such a screening routine, and monitor the individual's health throughout their life.

While database of disease-causing genotypes is an extremely important health issue, there will always be new genotypes which cannot be detected by such an approach before the clinical manifestation of the disease occurs. To associate a new genotype with a particular disease and reveal the molecular mechanism behind it will require applying the approaches described above. Perhaps in some limited cases, the molecular mechanism and the disease association of these new disease-causing mutations will be revealed by the means of experimental techniques or in model organisms, and then they will be added to the appropriate genotype database. However, in the vast majority of the cases, the molecular mechanism will have to be revealed in silico. Essentially, one should be able to address the following hypothetical scenario and provide a diagnosis for a particular individual: given an individual's genome, the goal is to identify all the potentially disease-causing mutations by comparing them to the databases of disease-causing genotypes. Then, the rest of the individual's DNA differences (with respect to the "standard" human DNA) must be analyzed in silico and disease-causing mutations must be identified among the DNA differences causing natural differences in human population. However, the completion of such a task is not trivial, because not only the distinction between disease-causing and harmless mutations is difficult, but also, more importantly, the linkage between predicted disease-causing mutations and the disease is extremely challenging, especially with complex diseases. Still developing biomarkers to personalize cancer treatment by identifying cancer-associated genes that can differentiate one type of cancer from another will enable the use of highly tailored therapies [187]. The problem is slightly less complicated for monogenic diseases, since the disease is known to be caused by the malfunction of a particular gene (protein) and if the given mutation in this protein is predicted to be diseasecausing, then, most probably, it is associated with the same monogenic disease. However, notable exceptions do exist, as, for example, missense mutations occurring in MECP2 gene and causing either Rett syndrome [188, 189], Huntington's disease [190], or other disorders [191].

\section{Pharmacogenomics}

With ever-increasing amount of clinical data, it is now widely understood that different races [192], ethnicities [193, 194], genders $[195,196]$, age $[197,198]$ groups, and so forth respond differently to various medications (Figure 2). A drug which is quite efficient for the treatment of a particular disease for a group of people sharing the same or a similar genotype may not work well for another group of people belonging to a different genotype. This may result from different phenotypes 
of the disease among these groups of people, but even if the phenotype is the same amongst the group members, still the efficacy of the drug may depend on the differences in the genotypes. A prominent example of differing drug responses is human cytochrome P450 [199]. One of the isoforms of human cytochrome P450, CYP2D6, is primarily responsible for metabolizing hydrocodone to hydromorphone, a typical drug treatment after surgery [200]. However, it was found that a variant of CYP2D6, the CYP2D6.17 common in African Americans, does not metabolize hydrocodone efficiently [201]. Having prior knowledge of such cases and even more importantly being able to predict the drug efficiency based on the patient's genome is crucial for successful treatment. If such information is readily available, then the prescription can be personalized by prescribing different dosages depending on the patient's genotype. Even further, frequently there are several drugs designed to treat certain diseases and the selection of the best drug for the treatment should be based on the patient's genotype as well. Currently, the data is very scarce [202-204] and much work must be done in order to make pharmacogenomics a more common practice.

\section{Personalized/Precise Medicine}

The culmination of the usefulness of the individual's genomic data resides in personalized medicine [205]. The basic concepts of personalized medicine, or sometimes called precision medicine, are outlined in a recent article [206]. Essentially, it is a combination or a joint venture of personalized diagnostics, pharmacogenomics, and personalized preventive care [207-209] (Figure 2). Since personalized diagnostics and pharmacogenomics were already discussed above, the main focus here is the personalized preventive care. Ignoring ethical issues associated with providing individuals with predictions about their long term health [210], an early preventive treatment for plausible disease would have enormous effect on society and the individuals themselves. Perhaps, preventive care can be divided into several categories: (a) preventive care for conditional diseases; (b) preventive care for development diseases; and (c) preventive care for an individual's lifetime.

The most easily addressable preventive care is the care for individuals who may develop a disease which depends on certain (environmental) conditions. Obviously, avoiding these conditions will dramatically decrease the disease risk. For example, Chronic Beryllium disease is a disorder found in some individuals being exposed to Beryllium [211] in addition to having a particular genotype. If every individual applying for a job in Beryllium rich environment is genotyped and individuals possessing the risk genotype are notified of this risk and potential dangers, then, this would be the best preventive care for people susceptible to Chronic Beryllium disease. Other examples are the cases of individuals predisposed to lung or skin cancers $[212,213]$. These individuals should avoid smoking or exposure to intense ultraviolet light, respectively. The list of examples can be extended to many other cases, but the message is that clear identification of individuals predisposed to diseases whose development depends on certain conditions would greatly decrease their reliance on medical treatment later on in life. In addition, in mental disorders the susceptibility profile of each individual depends on the psychosocial environment and this should be taken into account in delivering the prognosis [214].

Developmental diseases are typically quite severe and even if the patient survives, the effects are often permanent. Another important distinction between developmental diseases and other diseases is that once they are clinically manifested, it is typically too late for treatment. Due to the severity of these diseases, predicting an individual's genetic predispositions must be done at a very early stage in their development and the appropriate treatment must be administered [215].

Finally, there are many diseases and conditions which require a lifetime of care [216]. It is desirable that such cases are detected before the patient becomes sick. However, the preventive care in such a case, when the disease is still not manifested, will require quite different (from current) thinking from both the patient and the primary physician [217]. It may require decisions which will be difficult to justify without presence of the disease and in some cases may result in the wrong treatment. The straightforward solution is to avoid radical interventions but to subject these high risk patients to constant monitoring and frequent examinations.

\section{Concluding Remarks}

This paper attempts to outline the current development taking place in several rapidly evolving disciplines: personalized diagnostics, pharmacogenomics, and personalized medicine, and also how structural and conventional biology and in silico biophysics are embedded in these efforts. It is quite likely that individual genotyping will become a standard test, similar to currently used blood test, and the decisions about individual's health will be based on the corresponding genotype. The decisions about their health for either personalized preventive care or personalized treatment will be still individualized but not to the extent that each person will receive an individualized drug; rather, both the preventive care and drug prescription will be grouped into categories depending on common genotypes and phenotypes. With this in mind, structural and functional genomics along with better computational approaches will play crucial roles in the development of these methods.

However, many challenges still exist in fully utilizing genomic data to guide personalized medicine and pharmacogenomics [218]. Recent completion of the 1000 genomes pilot project [219] revealed that most individuals carry 250 to 300 loss-of-function variants in annotated genes and 50 to 100 variants previously implicated in inherited disorders [220]. In addition to this observation, it is known that the severity of a disease depends on many factors, and, for individual carrying the same disease-causing mutation(s), the manifestation can be quite different. At the same time, it was pointed out that disease-associated variants differ radically from variants observed in the 1000 genomes project dataset [221], providing a hope that, despite the natural complexity, the genetic 
information will be used to provide better diagnostics and treatment.

It should be pointed out that it is clear that personalized medicine and pharmacogenomics will never be totally "personal." The time and the effort to bring scientific discovery to the clinic, including the time for clinical trials, are prohibitively large and cannot be done on an individual basis. Instead, the causes of the diseases should be generalized into classes and specific, "individualized" treatment should be offered depending on individual's DNA defect falling into a specific class for which particular treatment does exist.

\section{Conflict of Interests}

The author declares that there is no conflict of interests regarding the publication of this paper.

\section{Acknowledgment}

The work was supported by an institutional grant from Clemson University, the office of the Provost.

\section{References}

[1] V. Kastelic and K. Drobnič, "A single-nucleotide polymorphism (SNP) multiplex system: the association of five SNPs with human eye and hair color in the Slovenian population and comparison using a Bayesian network and logistic regression model," Croatian Medical Journal, vol. 53, no. 5, pp. 401-408, 2012.

[2] T. J. Hoffmann, Y. Zhan, M. N. Kvale et al., "Design and coverage of high throughput genotyping arrays optimized for individuals of East Asian, African American, and Latino race/ethnicity using imputation and a novel hybrid SNP selection algorithm," Genomics, vol. 98, no. 6, pp. 422-430, 2011.

[3] J. M. de Gruijter, O. Lao, M. Vermeulen et al., "Contrasting signals of positive selection in genes involved in human skincolor variation from tests based on SNP scans and resequencing," Investigative Genetics, vol. 2, no. 1, article 24, 2011.

[4] S. Anno, T. Abe, and T. Yamamoto, "Interactions between SNP alleles at multiple loci contribute to skin color differences between caucasoid and mongoloid subjects," International Journal of Biological Sciences, vol. 4, no. 2, pp. 81-86, 2008.

[5] E. Alexov and M. Sternberg, "Understanding molecular effects of naturally occurring genetic differences," Journal of Molecular Biology, vol. 425, no. 21, pp. 3911-3913, 2013.

[6] R. R. Haraksingh and M. P. Snyder, "Impacts of variation in the human genome on gene regulation," Journal of Molecular Biology, vol. 425, no. 21, pp. 3970-3977, 2013.

[7] R. Chen, G. I. Mias, J. Li-Pook-Than et al., "Personal omics profiling reveals dynamic molecular and medical phenotypes," Cell, vol. 148, no. 6, pp. 1293-1307, 2012.

[8] H. Y. K. Lam, C. Pan, M. J. Clark et al., "Detecting and annotating genetic variations using the HugeSeq pipeline," Nature Biotechnology, vol. 30, no. 3, pp. 226-229, 2012.

[9] R. R. Haraksingh, A. Abyzov, M. Gerstein, A. E. Urban, and M. Snyder, "Genome-wide mapping of copy number variation in humans: comparative analysis of high resolution array platforms," PLoS ONE, vol. 6, no. 11, Article ID e27859, 2011.
[10] C. Genomes Project, G. R. Abecasis, A. Auton et al., "An integrated map of genetic variation from 1,092 human genomes," Nature, vol. 491, pp. 56-65, 2012.

[11] Genomes Project Consortium, G. R. Abecasis, D. Altshuler et al., "A map of human genome variation from population-scale sequencing," Nature, vol. 467, pp. 1061-1073, 2010.

[12] D. F. Conrad, D. Pinto, R. Redon et al., "Origins and functional impact of copy number variation in the human genome," Nature, vol. 464, no. 7289, pp. 704-712, 2010.

[13] R. Redon, S. Ishikawa, K. R. Fitch et al., "Global variation in copy number in the human genome," Nature, vol. 444, no. 7118, pp. 444-454, 2006.

[14] C. Gonzaga-Jauregui, J. R. Lupski, and R. A. Gibbs, "Human genome sequencing in health and disease," Annual Review of Medicine, vol. 63, pp. 35-61, 2012.

[15] C. G. van El, M. C. Cornel, P. Borry et al., "Whole-genome sequencing in health care: recommendations of the European society of human genetics," European Journal of Human Genetics, vol. 21, supplement 1, pp. S1-S5, 2013.

[16] C. E. Schwartz and C.-F. Chen, "Progress in detecting genetic alterations and their association with human disease," Journal of Molecular Biology, vol. 425, no. 21, pp. 3914-3918, 2013.

[17] O. R. Saramäki, K. K. Waltering, and T. Visakorpi, "Methods for identifying and studying genetic alterations in hormonedependent cancers.", Methods in molecular biology, vol. 505, pp. 263-277, 2009.

[18] N. Haiminen, D. N. Kuhn, L. Parida, and I. Rigoutsos, "Evaluation of methods for de novo genome assembly from highthroughput sequencing reads reveals dependencies that affect the quality of the results," PLoS ONE, vol. 6, no. 9, Article ID e24182, 2011.

[19] M. Scudellari, “The 24-hour, \$1,000 genome," Cancer Discovery, 2012.

[20] L. deFrancesco, "Life technologies promises \$1,000 genome," Nature biotechnology, vol. 30, article 126, 2012.

[21] E. R. Mardis, “The 1,000 genome, the 100,000 analysis?” Genome Medicine, vol. 2, no. 11, article 84, 2010.

[22] J. Wise, "Consortium hopes to sequence genome of 1000 volunteers," British Medical Journal, vol. 336, no. 7638, article 237, 2008.

[23] B. M. Kuehn, "1000 genomes project promises closer look at variation in human genome," The Journal of the American Medical Association, vol. 300, no. 23, article 2715, 2008.

[24] M. Pybus, G. M. Dallolio, P. Luisi et al., "1000 genomes selection browser 1.0: a genome browser dedicated to signatures of natural selection in modern humans," Nucleic Acids Research, 2013.

[25] J. Amberger, C. A. Bocchini, A. F. Scott, and A. Hamosh, "McKusick's Online Mendelian Inheritance in Man (OMIM)," Nucleic Acids Research, vol. 37, no. 1, pp. D793-D796, 2009.

[26] V. A. McKusick, "Mendelian Inheritance in Man and its online version, OMIM," The American Journal of Human Genetics, vol. 80, no. 4, pp. 588-604, 2007.

[27] H. J. W. Van Triest, D. Chen, X. Ji, S. Qi, and J. Li-Ling, "PhenOMIM: an OMIM-based secondary database purported for phenotypic comparison," in Proceedings of the 33rd Annual International Conference of the IEEE Engineering in Medicine and Biology Society (EMBS '11), pp. 3589-3592, September 2011.

[28] S. Rossi, A. Tsirigos, A. Amoroso et al., "OMiR: identification of associations between OMIM diseases and microRNAs," Genomics, vol. 97, no. 2, pp. 71-76, 2011. 
[29] R. Cohen, A. Gefen, M. Elhadad, and O. S. Birk, "CSI-OMIMclinical synopsis search in OMIM," BMC Bioinformatics, vol. 12, p. 65, 2011.

[30] C. D. Bajdik, B. Kuo, S. Rusaw, S. Jones, and A. BrooksWilson, "CGMIM: automated text-mining of Online Mendelian Inheritance in Man (OMIM) to identify genetically-associated cancers and candidate genes," BMC Bioinformatics, vol. 6, article 78, 2005.

[31] M. Bhagwat, "Searching NCBI's dbSNP database," in Current Protocols in Bioinformatics, chapter 1, unit 1.19, 2010.

[32] S. F. Saccone, J. Quan, G. Mehta et al., "New tools and methods for direct programmatic access to the dbSNP relational database," Nucleic Acids Research, vol. 39, no. 1, pp. D901-D907, 2011.

[33] S. Teng, T. Madej, A. Panchenko, and E. Alexov, "Modeling effects of human single nucleotide polymorphisms on proteinprotein interactions," Biophysical Journal, vol. 96, no. 6, pp. 2178-2188, 2009.

[34] Q. Cao, M. Zhou, X. Wang et al., "CaSNP: a database for interrogating copy number alterations of cancer genome from SNP array data," Nucleic Acids Research, vol. 39, no. 1, pp. D968D974, 2011.

[35] G. Tuteja, E. Cheng, H. Papadakis, and G. Bejerano, "PESNPdb: a comprehensive database of SNPs studied in association with pre-eclampsia," Placenta, vol. 33, no. 12, pp. 1055-1057, 2012.

[36] J. Reumers, J. Schymkowitz, J. Ferkinghoff-Borg, F. Stricher, L. Serrano, and F. Rousseau, "SNPeffect: a database mapping molecular phenotypic effects of human non-synonymous coding SNPs," Nucleic Acids Research, vol. 33, pp. D527-D532, 2005.

[37] X. Liu, X. Jian, and E. Boerwinkle, "dbNSFP: a lightweight database of human nonsynonymous SNPs and their functional predictions," Human Mutation, vol. 32, no. 8, pp. 894-899, 2011.

[38] L. Guo, Y. Du, S. Chang, K. Zhang, and J. Wang, "rSNPBase: a database for curated regulatory SNPs," Nucleic Acids Research, vol. 42, pp. D1033-D1039, 2014.

[39] T. Zhang, Q. Zhou, Y. Pang et al., "CYP-nsSNP: a specialized database focused on effect of non-synonymous SNPs on function of CYPs," Interdisciplinary Sciences: Computational Life Sciences, vol. 4, no. 2, pp. 83-89, 2012.

[40] S. Bhushan and N. B. Perumal, "Disease associated cytokine SNPs database: an annotation and dissemination model," Cytokine, vol. 57, no. 1, pp. 107-112, 2012.

[41] International HapMap Consortium, "The International HapMap Project," Nature, vol. 426, no. 6968, pp. 789-796, 2003.

[42] T. R. Magalhães, J. P. Casey, J. Conroy et al., "HGDP and HapMap analysis by Ancestry Mapper reveals local and global population relationships," PLoS ONE, vol. 7, no. 11, Article ID e49438, 2012.

[43] Y. J. Sung, C. C. Gu, H. K. Tiwari, D. K. Arnett, U. Broeckel, and D. C. Rao, "Genotype imputation for African Americans using data from HapMap phase II versus 1000 genomes projects," Genetic Epidemiology, vol. 36, no. 5, pp. 508-516, 2012.

[44] X. Gao, T. Haritunians, P. Marjoram et al., "Genotype imputation for Latinos using the HapMap and 1000 Genomes Project reference panels," Frontiers in Genetics, vol. 3, article 117, 2012.

[45] S. Garte, "Human population genetic diversity as a function of SNP type from HapMap data," American Journal of Human Biology, vol. 22, no. 3, pp. 297-300, 2010.

[46] C.-T. Liu, H. Lin, and H. Lin, "Functional analysis of HapMap SNPs," Gene, vol. 511, no. 2, pp. 358-363, 2012.
[47] A. K. Mitra, K. R. Crews, S. Pounds et al., "Genetic variants in cytosolic $5^{\prime}$-nucleotidase II are associated with its expression and cytarabine sensitivity in HapMap cell lines and in patients with acute myeloid leukemia," Journal of Pharmacology and Experimental Therapeutics, vol. 339, no. 1, pp. 9-23, 2011.

[48] X. Cao, A. K. Mitra, S. Pounds et al., "RRM1 and RRM2 pharmacogenetics: association with phenotypes in HapMap cell lines and acute myeloid leukemia patients," Pharmacogenomics, vol. 14, no. 12, pp. 1449-1466, 2013.

[49] T. Yamamura, J. Hikita, M. Bleakley et al., "HapMap SNP Scanner: an online program to mine SNPs responsible for cell phenotype," Tissue Antigens, vol. 80, no. 2, pp. 119-125, 2012.

[50] S. Stefl, H. Nishi, M. Petukh, A. R. Panchenko, and E. Alexov, "Molecular mechanisms of disease-causing missense mutations," Journal of Molecular Biology, vol. 425, pp. 3919-3936, 2013.

[51] Z. Zhang, M. A. Miteva, L. Wang, and E. Alexov, "Analyzing effects of naturally occurring missense mutations," Computational and Mathematical Methods in Medicine, vol. 2012, Article ID 805827, 2012.

[52] S. Teng, E. Michonova-Alexova, and E. Alexov, "Approaches and resources for prediction of the effects of non-synonymous single nucleotide polymorphism on protein function and interactions," Current Pharmaceutical Biotechnology, vol. 9, no. 2, pp. 123-133, 2008.

[53] B. V. Halldorsson and R. Sharan, "Network-based interpretation of genomic variation data," The Journal of Molecular Biology, vol. 425, pp. 3964-3969, 2013.

[54] A. Califano, A. J. Butte, S. Friend, T. Ideker, and E. Schadt, "Leveraging models of cell regulation and GWAS data in integrative network-based association studies," Nature Genetics, vol. 44, no. 8, pp. 841-847, 2012.

[55] M. E. Smoot, K. Ono, J. Ruscheinski, P. Wang, and T. Ideker, "Cytoscape 2.8: new features for data integration and network visualization," Bioinformatics, vol. 27, no. 3, Article ID btq675, pp. 431-432, 2011.

[56] R. Saito, M. E. Smoot, K. Ono et al., "A travel guide to Cytoscape plugins," Nature Methods, vol. 9, no. 11, pp. 1069-1076, 2012.

[57] M. Smoot, K. Ono, T. Ideker, and S. Maere, "PiNGO: a cytoscape plugin to find candidate genes in biological networks," Bioinformatics, vol. 27, no. 7, pp. 1030-1031, 2011.

[58] M. S. Cline, M. Smoot, E. Cerami et al., "Integration of biological networks and gene expression data using Cytoscape.," Nature Protocols, vol. 2, no. 10, pp. 2366-2382, 2007.

[59] C. M. Tan, E. Y. Chen, R. Dannenfelser, N. R. Clark, and A. Ma'Ayan, "Network2Canvas: network visualization on a canvas with enrichment analysis," Bioinformatics, vol. 29, no. 15, pp. 1872-1878, 2013.

[60] S. Turkarslan, E. J. Wurtmann, W. J. Wu et al., "Network portal: a database for storage, analysis and visualization of biological networks," Nucleic Acids Research, vol. 42, pp. D184-D190, 2014.

[61] W. Li, L. N. Kinch, and N. V. Grishin, "Pclust: protein network visualization highlighting experimental data," Bioinformatics, vol. 29 , no. 20, pp. 2647-2648, 2013.

[62] D. Hurley, H. Araki, Y. Tamada et al., "Gene network inference and visualization tools for biologists: application to new human transcriptome datasets," Nucleic Acids Research, vol. 40, no. 6, pp. 2377-2398, 2012.

[63] P. Fariselli, O. Olmea, A. Valencia, and R. Casadio, "Progress in predicting inter-residue contacts of proteins with neural networks and correlated mutations," Proteins: Structure, Function and Genetics, vol. 45, no. 5, pp. 157-162, 2001. 
[64] F. Pazos, M. Helmer-Citterich, G. Ausiello, and A. Valencia, "Correlated mutations contain information about proteinprotein interaction," Journal of Molecular Biology, vol. 271, no. 4, pp. 511-523, 1997.

[65] H. Nishi, M. Tyagi, S. Teng et al., "Cancer missense mutations alter binding properties of proteins and their interaction networks," PLoS ONE, vol. 8, no. 6, Article ID e66273, 2013.

[66] K. Takano, D. Liu, P. Tarpey et al., "An x-linked channelopathy with cardiomegaly due to a CLIC2 mutation enhancing ryanodine receptor channel activity," Human Molecular Genetics, vol. 21, no. 20, pp. 4497-4507, 2012.

[67] T. K. B. Gandhi, J. Zhong, S. Mathivanan et al., "Analysis of the human protein interactome and comparison with yeast, worm and fly interaction datasets," Nature Genetics, vol. 38, no. 3, pp. 285-293, 2006.

[68] A. Ghavidel, G. Cagney, and A. Emili, "A skeleton of the human protein interactome," Cell, vol. 122, no. 6, pp. 830-832, 2005.

[69] K. Rajapakse, D. Drobne, D. Kastelec, and R. Marinsek-Logar, "Experimental evidence of false-positive Comet test results due to $\mathrm{TiO}_{2}$ particle-assay interactions," Nanotoxicology, vol. 7, no. 5, pp. 1043-1051, 2013.

[70] T. N. Nguyen and J. A. Goodrich, "Protein-protein interaction assays: eliminating false positive interactions," Nature Methods, vol. 3, no. 2, pp. 135-139, 2006.

[71] S. Foerster, T. Kacprowski, V. M. Dhople et al., "Characterization of the EGFR interactome reveals associated protein complex networks and intracellular receptor dynamics," Proteomics, vol. 13, pp. 3131-3144, 2013.

[72] H. Bohnenberger, T. Oellerich, M. Engelke, H. H. Hsiao, H. Urlaub, and J. Wienands, "Complex phosphorylation dynamics control the composition of the Syk interactome in B cells," European Journal of Immunology, vol. 41, no. 6, pp. 1550-1562, 2011.

[73] E. Guney and B. Oliva, "Analysis of the robustness of networkbased disease-gene prioritization methods reveals redundancy in the human interactome and functional diversity of diseasegenes," PLoS ONE, vol. 9, no. 4, Article ID e94686, 2014.

[74] J. Love, F. Mancia, L. Shapiro et al., "The New York Consortium on Membrane Protein Structure (NYCOMPS): a highthroughput platform for structural genomics of integral membrane proteins," Journal of Structural and Functional Genomics, vol. 11, no. 3, pp. 191-199, 2010.

[75] R. Xiao, S. Anderson, J. Aramini et al., “The high-throughput protein sample production platform of the Northeast Structural Genomics Consortium," Journal of Structural Biology, vol. 172, no. 1, pp. 21-33, 2010.

[76] Z. Wunderlich, T. B. Acton, J. Liu et al., "The protein target list of the northeast structural genomics consortium," Proteins, vol. 56, no. 2, pp. 181-187, 2004.

[77] A. R. Williamson, "Creating a structural genomics consortium," Nature Structural Biology, vol. 7, p. 953, 2000.

[78] E. Portugaly, I. Kifer, and M. Linial, "Selecting targets for structural determination by navigating in a graph of protein families," Bioinformatics, vol. 18, no. 7, pp. 899-907, 2002.

[79] P. W. Rose, C. Bi, W. F. Bluhm et al., "The RCSB protein data bank: new resources for research and education," Nucleic Acids Research, vol. 41, no. 1, pp. D475-D482, 2013.

[80] H. M. Berman, G. J. Kleywegt, H. Nakamura, and J. L. Markley, "Mini review: the future of the protein data bank," Biopolymers, vol. 99, no. 3, pp. 218-222, 2013.
[81] Y. Zhang, "I-TASSER server for protein 3D structure prediction," BMC Bioinformatics, vol. 9, article 40, 2008.

[82] D. M. Dunlavy, D. P. O'Leary, D. Klimov, and D. Thirumalai, "HOPE: a homotopy optimization method for protein structure prediction," Journal of Computational Biology, vol. 12, no. 10, pp. 1275-1288, 2005.

[83] D. Kihara, H. Lu, A. Kolinski, and J. Skolnick, "TOUCHSTONE: an ab initio protein structure prediction method that uses threading-based tertiary restraints," Proceedings of the National Academy of Sciences of the United States of America, vol. 98, no. 18, pp. 10125-10130, 2001.

[84] S. D. Pickett, M. A. Saqi, and M. J. Sternberg, "Evaluation of the sequence template method for protein structure prediction: discrimination of the (beta/alpha)8-barrel fold," Journal of Molecular Biology, vol. 228, no. 1, pp. 170-187, 1992.

[85] W. Qu, H. Sui, B. Yang, and W. Qian, "Improving protein secondary structure prediction using a multi-modal BP method," Computers in Biology and Medicine, vol. 41, no. 10, pp. 946-959, 2011.

[86] Q. Cong, L. N. Kinch, J. Pei et al., "An automatic method for CASP9 free modeling structure prediction assessment," Bioinformatics, vol. 27, no. 24, pp. 3371-3378, 2011.

[87] D. Petrey, Z. Xiang, C. L. Tang et al., "Using multiple structure alignments, fast model building, and energetic analysis in fold recognition and homology modeling," Proteins: Structure, Function and Genetics, vol. 53, supplement 6, pp. 430-435, 2003.

[88] A. Kryshtafovych, K. Fidelis, and J. Moult, "CASP9 results compared to those of previous casp experiments," Proteins: Structure, Function and Bioinformatics, vol. 82, supplement 2, pp. 164-174, 2014.

[89] B. Stieglitz, L. F. Haire, I. Dikic, and K. Rittinger, "Structural analysis of SHARPIN, a subunit of a large multi-protein E3 ubiquitin ligase, reveals a novel dimerization function for the pleckstrin homology superfold," Journal of Biological Chemistry, vol. 287, no. 25, pp. 20823-20829, 2012.

[90] A. Silkov, Y. Yoon, H. Lee et al., "Genome-wide structural analysis reveals novel membrane binding properties of AP180 Nterminal homology (ANTH) domains," The Journal of Biological Chemistry, vol. 286, no. 39, pp. 34155-34163, 2011.

[91] P. Kundrotas, P. Georgieva, A. Shoshieva, P. Christova, and E. Alexova, "Assessing the quality of the homology-modeled 3D structures from electrostatic standpoint: test on bacterial nucleoside monophosphate kinase families," Journal of Bioinformatics and Computational Biology, vol. 5, no. 3, pp. 693-715, 2007.

[92] Z. Zhang, S. Witham, M. Petukh et al., "A rational free energy-based approach to understanding and targeting diseasecausing missense mutations," Journal of the American Medical Informatics Association, vol. 20, no. 4, pp. 643-651, 2013.

[93] L. F. Agnati, A. O. Tarakanov, S. Ferré, K. Fuxe, and D. Guidolin, "Receptor-receptor interactions, receptor mosaics, and basic principles of molecular network organization: possible implications for drug development," Journal of Molecular Neuroscience, vol. 26, no. 2-3, pp. 193-208, 2005.

[94] J. R. Perkins, I. Diboun, B. H. Dessailly, J. G. Lees, and C. Orengo, "Transient protein-protein interactions: structural, functional, and network properties," Structure, vol. 18, no. 10, pp. 1233-1243, 2010.

[95] X. Kuang, J. G. Han, N. Zhao, B. Pang, C. Shyu, and D. Korkin, "DOMMINO: a database of macromolecular interactions," Nucleic Acids Research, vol. 40, no. 1, pp. D501-D506, 2012. 
[96] A. A. Das, O. P. Sharma, M. S. Kumar, R. Krishna, and P. P. Mathur, "PepBind: a comprehensive database and computational tool for analysis of protein-peptide interactions," Genomics, Proteomics \& Bioinformatics, vol. 11, no. 4, pp. 241246, 2013

[97] R. Rid, W. Strasser, D. Siegl et al., "PRIMOS: an integrated database of reassessed protein-protein interactions providing web-based access to in silico validation of experimentally derived data," Assay and Drug Development Technologies, vol. 11, no. 5, pp. 333-346, 2013.

[98] S. Kikugawa, K. Nishikata, K. Murakami et al., "PCDq: human protein complex database with quality index which summarizes different levels of evidences of protein complexes predicted from $\mathrm{h}$-invitational protein-protein interactions integrative dataset.", BMC Systems Biology, vol. 6, supplement 2, p. S7, 2012.

[99] I. H. Moal and J. Fernández-Recio, "SKEMPI: a structural kinetic and energetic database of mutant protein interactions and its use in empirical models," Bioinformatics, vol. 28, no. 20, pp. 2600-2607, 2012.

[100] M. N. Wass, A. David, and M. J. Sternberg, "Challenges for the prediction of macromolecular interactions," Current Opinion in Structural Biology, vol. 21, no. 3, pp. 382-390, 2011.

[101] D. Baker, "Prediction and design of macromolecular structures and interactions," Philosophical Transactions of the Royal Society $B$, vol. 361, pp. 459-463, 2006.

[102] V. A. Roberts, M. E. Pique, L. F. Ten Eyck, and S. Li, "Predicting protein-DNA interactions by full search computational docking," Proteins, vol. 81, pp. 2106-2118, 2013.

[103] T. Clancy, E. A. Rødland, S. Nygard, and E. Hovig, "Predicting physical interactions between protein complexes," Molecular and Cellular Proteomics, vol. 12, no. 6, pp. 1723-1734, 2013.

[104] N. Fukuhara and T. Kawabata, "HOMCOS: a server to predict interacting protein pairs and interacting sites by homology modeling of complex structures," Nucleic Acids Research, vol. 36, pp. W185-W189, 2008.

[105] M. Takeda-Shitaka, G. Terashi, C. Chiba, D. Takaya, and H. Umeyama, "FAMS Complex: a fully automated homology modeling protein complex structures," Medicinal Chemistry, vol. 2, no. 2, pp. 191-201, 2006.

[106] P. J. Kundrotas, M. F. Lensink, and E. Alexov, "Homology-based modeling of 3D structures of protein-protein complexes using alignments of modified sequence profiles," International Journal of Biological Macromolecules, vol. 43, no. 2, pp. 198-208, 2008.

[107] P. Kundrotas and E. Alexov, "Predicting interacting and interfacial residues using continuous sequence segments," International Journal of Biological Macromolecules, vol. 41, no. 5, pp. 615-623, 2007.

[108] G. Launay and T. Simonson, "Homology modelling of proteinprotein complexes: a simple method and its possibilities and limitations," BMC Bioinformatics, vol. 9, article 427, 2008.

[109] M. van Dijk and A. M. J. J. Bonvin, "Pushing the limits of what is achievable in protein-DNA docking: benchmarking HADDOCK's performance," Nucleic Acids Research, vol. 38, no. 17, Article ID gkq222, pp. 5634-5647, 2010.

[110] P. Carter, V. I. Lesk, S. A. Islam, and M. J. E. Sternberg, "Proteinprotein docking using 3D-Dock in rounds 3,4 , and 5 of CAPRI," Proteins: Structure, Function and Genetics, vol. 60, no. 2, pp. 281288, 2005.

[111] D. Kozakov, R. Brenke, S. R. Comeau, and S. Vajda, "PIPER: an FFT-based protein docking program with pairwise potentials," Proteins: Structure, Function and Genetics, vol. 65, no. 2, pp. 392406, 2006.
[112] S. Liang, G. Wang, and Y. Zhou, "Refining near-native proteinprotein docking decoys by local resampling and energy minimization," Proteins, vol. 76, no. 2, pp. 309-316, 2009.

[113] M. F. Lensink and S. J. Wodak, "Docking, scoring, and affinity prediction in CAPRI," Proteins, vol. 81, pp. 2082-2095, 2013.

[114] M. F. Lensink, I. H. Moal, P. A. Bates et al., "Blind prediction of interfacial water positions in CAPRI," Proteins, vol. 82, no. 4, pp. 620-632, 2014.

[115] M. F. Lensink and S. J. Wodak, "Blind predictions of protein interfaces by docking calculations in CAPRI," Proteins: Structure, Function and Bioinformatics, vol. 78, no. 15, pp. 3085-3095, 2010.

[116] M. F. Lensink and S. J. Wodak, "Docking and scoring protein interactions: CAPRI 2009," Proteins: Structure, Function and Bioinformatics, vol. 78, no. 15, pp. 3073-3084, 2010.

[117] D. Beglov, D. R. Hall, R. Brenke et al., "Minimal ensembles of side chain conformers for modeling protein-protein interactions," Proteins: Structure, Function and Bioinformatics, vol. 80, no. 2, pp. 591-601, 2012.

[118] Q. Wang, A. A. Canutescu, and R. L. Dunbrack Jr., "SCWRL and MolIDE: computer programs for side-chain conformation prediction and homology modeling," Nature Protocols, vol. 3, no. 12, pp. 1832-1847, 2008.

[119] M. J. Bower, F. E. Cohen, and R. L. Dunbrack Jr., "Prediction of protein side-chain rotamers from a backbone-dependent rotamer library: a new homology modeling tool," Journal of Molecular Biology, vol. 267, no. 5, pp. 1268-1282, 1997.

[120] Z. Xiang, P. J. Steinbach, M. P. Jacobson, R. A. Friesner, and B. Honig, "Prediction of side-chain conformations on protein surfaces," Proteins: Structure, Function and Genetics, vol. 66, no. 4, pp. 814-823, 2007.

[121] Z. Xiang and B. Honig, "Extending the accuracy limits of prediction for side-chain conformations," Journal of Molecular Biology, vol. 311, no. 2, pp. 421-430, 2001.

[122] S. Liang, C. Zhang, and Y. Zhou, "LEAP: highly accurate prediction of protein loop conformations by integrating coarsegrained sampling and optimized energy scores with all-atom refinement of backbone and side chains," Journal of Computational Chemistry, vol. 35, no. 4, pp. 335-341, 2014.

[123] K. Zhu and T. Day, "Ab initio structure prediction of the antibody hypervariable H3 loop," Proteins: Structure, Function and Bioinformatics, vol. 81, no. 6, pp. 1081-1089, 2013.

[124] S. Zhao, K. Zhu, J. Li, and R. A. Friesner, "Progress in super long loop prediction," Proteins: Structure, Function and Bioinformatics, vol. 79, no. 10, pp. 2920-2935, 2011.

[125] N. M. Glykos and M. Kokkinidis, "Meaningful refinement of polyalanine models using rigid-body simulated annealing: application to the structure determination of the A31P Rop mutant," Acta Crystallographica Section D: Biological Crystallography, vol. 55, no. 7, pp. 1301-1308, 1999.

[126] Z. Zhang, S. Teng, L. Wang, C. E. Schwartz, and E. Alexov, "Computational analysis of missense mutations causing SnyderRobinson syndrome," Human Mutation, vol. 31, no. 9, pp. $1043-$ 1049, 2010.

[127] N. Dolzhanskaya, M. A. Gonzalez, F. Sperziani et al., "A novel p.Leu(381)Phe mutation in presenilin 1 is associated with very early onset and unusually fast progressing dementia as well as lysosomal inclusions typically seen in Kufs disease," Journal of Alzheimer's Disease, vol. 39, no. 1, pp. 23-27, 2013.

[128] L. Boccuto, K. Aoki, H. Flanagan-Steet et al., "A mutation in a ganglioside biosynthetic enzyme, ST3GAL5, results in salt 
\& pepper syndrome, a neurocutaneous disorder with altered glycolipid and glycoprotein glycosylation," Human Molecular Genetics, vol. 23, no. 2, pp. 418-433, 2014.

[129] C. M. Yates and M. J. E. Sternberg, "The effects of nonsynonymous single nucleotide polymorphisms (nsSNPs) on protein-protein interactions," Journal of Molecular Biology, vol. 425, pp. 3949-3963, 2013.

[130] M. Hecht, Y. Bromberg, and B. Rost, "News from the protein mutability landscape," Journal of Molecular Biology, vol. 425, no. 21, pp. 3937-3948, 2013.

[131] Z. Zhang, J. Norris, C. Schwartz, and E. Alexov, "In silico and in vitro investigations of the mutability of disease-causing missense mutation sites in spermine synthase," PLoS ONE, vol. 6, no. 5, Article ID e20373, 2011.

[132] L. Wickstrom, E. Gallicchio, and R. M. Levy, "The linear interaction energy method for the prediction of protein stability changes upon mutation," Proteins: Structure, Function and Bioinformatics, vol. 80, no. 1, pp. 111-125, 2012.

[133] Y. Li and J. Fang, "PROTS-RF: a robust model for predicting mutation-induced protein stability changes," PLOS ONE, vol. 7, no. 10, Article ID e47247, 2012.

[134] E. H. Kellogg, A. Leaver-Fay, and D. Baker, "Role of conformational sampling in computing mutation-induced changes in protein structure and stability," Proteins: Structure, Function and Bioinformatics, vol. 79, no. 3, pp. 830-838, 2011.

[135] Y. Dehouck, J. M. Kwasigroch, D. Gilis, and M. Rooman, "PoPMuSiC 2.1: a web server for the estimation of protein stability changes upon mutation and sequence optimality," $B M C$ Bioinformatics, vol. 12, article 151, 2011.

[136] C. M. Frenz, "Neural network-based prediction of mutationinduced protein stability changes in staphylococcal nuclease at 20 residue positions," Proteins: Structure, Function and Genetics, vol. 59, no. 2, pp. 147-151, 2005.

[137] E. Capriotti, P. Fariselli, and R. Casadio, "I-Mutant2.0: predicting stability changes upon mutation from the protein sequence or structure," Nucleic Acids Research, vol. 33, no. 2, pp. W306W310, 2005.

[138] G. Thiltgen and R. A. Goldstein, "Assessing predictors of changes in protein stability upon mutation using selfconsistency," PLoS ONE, vol. 7, no. 10, Article ID e46084, 2012.

[139] S. Khan and M. Vihinen, "Performance of protein stability predictors," Human Mutation, vol. 31, no. 6, pp. 675-684, 2010.

[140] K. Schurmann, M. Anton, I. Ivanov, C. Richter, H. Kuhn, and M. Walther, "Molecular basis for the reduced catalytic activity of the naturally occurring T560m mutant of human 12/15-lipoxygenase that has been implicated in coronary artery disease," Journal of Biological Chemistry, vol. 286, no. 27, pp. 23920-23927, 2011.

[141] S. Wang, W. Zhao, H. Liu, H. Gong, and Y. Yan, "Increasing $\beta$ B1-crystallin sensitivity to proteolysis caused by the congenital cataract-microcornea syndrome mutation S129R," Biochimica et Biophysica Acta, vol. 1832, no. 2, pp. 302-311, 2013.

[142] S. Witham, K. Takano, C. Schwartz, and E. Alexov, "A missense mutation in CLIC2 associated with intellectual disability is predicted by in silico modeling to affect protein stability and dynamics," Proteins: Structure, Function and Bioinformatics, vol. 79, no. 8, pp. 2444-2454, 2011.

[143] H. Tsukamoto and D. L. Farrens, "A constitutively activating mutation alters the dynamics and energetics of a key conformational change in a ligand-free $G$ protein-coupled receptor," The Journal of Biological Chemistry, vol. 288, pp. 28207-28216, 2013.
[144] J. Y. Lee and D. S. Kim, "Dramatic effect of single-base mutation on the conformational dynamics of human telomeric G-quadruplex," Nucleic Acids Research, vol. 37, no. 11, pp. 36253634, 2009.

[145] R. Guerois, J. E. Nielsen, and L. Serrano, "Predicting changes in the stability of proteins and protein complexes: a study of more than 1000 mutations," Journal of Molecular Biology, vol. 320, no. 2, pp. 369-387, 2002.

[146] Y. Dehouck, J. M. Kwasigroch, M. Rooman, and D. Gilis, "BeAtMuSiC: prediction of changes in protein-protein binding affinity on mutations," Nucleic Acids Research, vol. 41, pp. W333W339, 2013.

[147] A. Benedix, C. M. Becker, B. L. de Groot, A. Caflisch, and R. A. Böckmann, "Predicting free energy changes using structural ensembles," Nature Methods, vol. 6, no. 1, pp. 3-4, 2009.

[148] T. Kortemme and D. Baker, "A simple physical model for binding energy hot spots in protein-protein complexes," Proceedings of the National Academy of Sciences of the United States of America, vol. 99, no. 22, pp. 14116-14121, 2002.

[149] G. Rastelli, A. Del Rio, G. Degliesposti, and M. Sgobba, "Fast and accurate predictions of binding free energies using MMPBSA and MM-GBSA," Journal of Computational Chemistry, vol. 31, no. 4, pp. 797-810, 2010.

[150] V. Z. Spassov and L. Yan, "pH-selective mutagenesis of proteinprotein interfaces: in silico design of therapeutic antibodies with prolonged half-life," Proteins: Structure, Function and Bioinformatics, vol. 81, no. 4, pp. 704-714, 2013.

[151] R. Moretti, S. J. Fleishman, R. Agius, M. Torchala, and P. A. Bates, "Community-wide evaluation of methods for predicting the effect of mutations on protein-protein interactions," Proteins, vol. 81, pp. 1980-1987, 2013.

[152] A. David, R. Razali, M. N. Wass, and M. J. E. Sternberg, "Protein-protein interaction sites are hot spots for diseaseassociated nonsynonymous SNPs," Human Mutation, vol. 33, no. 2, pp. 359-363, 2012.

[153] Y. Zhang, M. Motamed, J. Seemann, M. S. Brown, and J. L. Goldstein, "Point mutation in luminal Loop 7 of scap protein blocks interaction with Loop 1 and abolishes movement to Golgi," The Journal of Biological Chemistry, vol. 288, no. 20, pp. 14059-14067, 2013.

[154] B. A. Shoemaker, D. Zhang, M. Tyagi et al., "IBIS (Inferred Biomolecular Interaction Server) reports, predicts and integrates multiple types of conserved interactions for proteins," Nucleic Acids Research, vol. 40, no. 1, pp. D834-D840, 2012.

[155] E. W. Sayers, T. Barrett, D. A. Benson et al., "Database resources of the National Center for Biotechnology Information," Nucleic Acids Research, vol. 40, no. 1, pp. D13-D25, 2012.

[156] K. Talley and E. Alexov, "On the pH-optimum of activity and stability of proteins," Proteins: Structure, Function and Bioinformatics, vol. 78, no. 12, pp. 2699-2706, 2010.

[157] E. Alexov, "Numerical calculations of the $\mathrm{pH}$ of maximal protein stability: the effect of the sequence composition and three-dimensional structure," European Journal of Biochemistry, vol. 271, no. 1, pp. 173-185, 2004.

[158] P. Chan and J. Warwicker, "Evidence for the adaptation of protein $\mathrm{pH}$-dependence to subcellular $\mathrm{pH}$, , BMC Biology, vol. 7, article 69, 2009.

[159] P. Chan, J. Lovrić, and J. Warwicker, "Subcellular $\mathrm{pH}$ and predicted $\mathrm{pH}$-dependent features of proteins," Proteomics, vol. 6, no. 12, pp. 3494-3501, 2006. 
[160] A. V. Onufriev and E. Alexov, "Protonation and pK changes in protein-ligand binding," Quarterly Reviews of Biophysics, vol. 46, no. 2, pp. 181-209, 2013.

[161] M. Kimura, J. Machida, S. Yamaguchi, A. Shibata, and T. Tatematsu, "Novel nonsense mutation in MSX1 in familial nonsyndromic oligodontia: subcellular localization and role of homeodomain/MH4," European Journal of Oral Sciences, vol. 122, no. 1, pp. 15-20, 2014.

[162] Y. Erzurumlu, F. Aydin Kose, O. Gozen, D. Gozuacik, E. A. Toth, and P. Ballar, "A unique IBMPFD-related P97/VCP mutation with differential binding pattern and subcellular localization," International Journal of Biochemistry and Cell Biology, vol. 45, no. 4, pp. 773-782, 2013.

[163] Y. Hosaka, H. Hanawa, T. Washizuka et al., "Function, subcellular localization and assembly of a novel mutation of KCNJ2 in Andersen's syndrome," Journal of Molecular and Cellular Cardiology, vol. 35, no. 4, pp. 409-415, 2003.

[164] P. J. Kundrotas and E. Alexov, "Electrostatic properties of protein-protein complexes," Biophysical Journal, vol. 91, no. 5, pp. 1724-1736, 2006.

[165] R. C. Mitra, Z. Zhang, and E. Alexov, "In silico modeling of pH-optimum of protein-protein binding," Proteins: Structure, Function and Bioinformatics, vol. 79, no. 3, pp. 925-936, 2011.

[166] M. Petukh, S. Stefl, and E. Alexov, "The role of protonation states in ligand-receptor recognition and binding," Current Pharmaceutical Design, vol. 19, no. 23, pp. 4182-4190, 2013.

[167] B. Aguilar, R. Anandakrishnan, J. Z. Ruscio, and A. V. Onufriev, "Statistics and physical origins of $\mathrm{pK}$ and ionization state changes upon protein-ligand binding," Biophysical Journal, vol. 98, no. 5, pp. 872-880, 2010.

[168] E. Alexov, E. L. Mehler, N. Baker et al., "Progress in the prediction of pKa values in proteins," Proteins: Structure, Function and Bioinformatics, vol. 79, no. 12, pp. 3260-3275, 2011.

[169] T. Carstensen, D. Farrell, Y. Huang, N. A. Baker, and J. E. Nielsen, "On the development of protein pKa calculation algorithms," Proteins: Structure, Function and Bioinformatics, vol. 79, no. 12, pp. 3287-3298, 2011.

[170] O. Emanuelsson, S. Brunak, G. von Heijne, and H. Nielsen, "Locating proteins in the cell using TargetP, SignalP and related tools," Nature Protocols, vol. 2, no. 4, pp. 953-971, 2007.

[171] A. Höglund, P. Dönnes, T. Blum, H. Adolph, and O. Kohlbacher, "MultiLoc: prediction of protein subcellular localization using $\mathrm{N}$-terminal targeting sequences, sequence motifs and amino acid composition," Bioinformatics, vol. 22, no. 10, pp. 1158-1165, 2006.

[172] P. Horton, K. Park, T. Obayashi et al., "WoLF PSORT: protein localization predictor," Nucleic Acids Research, vol. 35, no. 2, pp. W585-W587, 2007.

[173] K. J. Won, X. Zhang, T. Wang et al., "Comparative annotation of functional regions in the human genome using epigenomic data," Nucleic Acids Research, vol. 41, no. 8, pp. 4423-4432, 2013.

[174] A. B. Munkacsi, A. F. Porto, and S. L. Sturley, "NiemannPick type $\mathrm{C}$ disease proteins: orphan transporters or membrane rheostats?" Future Lipidology, vol. 2, no. 3, pp. 357-367, 2007.

[175] D. Avram, A. Fields, K. Pretty On Top, D. J. Nevrivy, J. E. Ishmael, and M. Leid, "Isolation of a novel family of $\mathrm{C}_{2} \mathrm{H}_{2}$ zinc finger proteins implicated in transcriptional repression mediated by chicken ovalbumin upstream promoter transcription factor (COUP-TF) orphan nuclear receptors," The Journal of Biological Chemistry, vol. 275, no. 14, pp. 10315-10322, 2000.
[176] J. Harrow, A. Frankish, J. M. Gonzalez et al., "GENCODE: the reference human genome annotation for the ENCODE project," Genome Research, vol. 22, no. 9, pp. 1760-1774, 2012.

[177] H. Chen, Y. Tian, W. Shu, X. Bo, and S. Wang, "Comprehensive identification and annotation of cell type-specific and ubiquitous CTCF-binding sites in the human genome," PLOS ONE, vol. 7, Article ID e41374, 2012.

[178] H. Jia, M. Osak, G. K. Bogu, L. W. Stanton, R. Johnson, and L. Lipovich, "Genome-wide computational identification and manual annotation of human long noncoding RNA genes," $R N A$, vol. 16, no. 8, pp. 1478-1487, 2010.

[179] R. Guigó, P. Flicek, J. F. Abril et al., "EGASP: the human ENCODE Genome Annotation Assessment Project," Genome Biology, vol. 7, supplement 1, article S2, 31 pages, 2006.

[180] P. Radivojac, W. T. Clark, T. R. Oron et al., "A large-scale evaluation of computational protein function prediction," Nature Methods, vol. 10, pp. 221-227, 2013.

[181] J. Gillis and P. Pavlidis, "Characterizing the state of the art in the computational assignment of gene function: Lessons from the first critical assessment of functional annotation (CAFA)," BMC Bioinformatics, vol. 14, no. 3, article S15, 2013.

[182] Z. Zhang, Y. Zheng, M. Petukh, A. Pegg, Y. Ikeguchi, and E. Alexov, "Enhancing human spermine synthase activity by engineered mutations," PLoS Computational Biology, vol. 9, no. 2, Article ID e1002924, 2013.

[183] Z. Zhang, J. Norris, V. Kalscheuer et al., "A Y328C missense mutation in spermine synthase causes a mild form of snyderrobinson syndrome," Human Molecular Genetics, vol. 22, no. 18, pp. 3789-3797, 2013.

[184] D. H. Spencer, K. L. Bubb, and M. V. Olson, "Detecting disease-causing mutations in the human genome by haplotype matching," American Journal of Human Genetics, vol. 79, no. 5, pp. 958-964, 2006.

[185] B. B. Fitterer, N. A. Antonishyn, P. L. Hall, and D. C. Lehotay, “A polymerase chain reaction-based genotyping assay for detecting a novel sandhoff disease-causing mutation," Genetic Testing and Molecular Biomarkers, vol. 16, no. 5, pp. 401-405, 2012.

[186] A. J. P. Smith, J. Palmen, W. Putt, P. J. Talmud, S. E. Humphries, and F. Drenos, "Application of statistical and functional methodologies for the investigation of genetic determinants of coronary heart disease biomarkers: lipoprotein lipase genotype and plasma triglycerides as an exemplar," Human Molecular Genetics, vol. 19, no. 20, Article ID ddq308, pp. 3936-3947, 2010.

[187] S. D. Ramsey, D. Veenstra, S. R. Tunis, L. Garrison, J. J. Crowley, and L. H. Baker, "How comparative effectiveness research can help advance "personalized medicine" in cancer treatment," Health Affairs, vol. 30, no. 12, pp. 2259-2268, 2011.

[188] C. A. Chapleau, J. Lane, J. Larimore, W. Li, L. Pozzo-Miller, and A. K. Percy, "Recent progress in Rett syndrome and MECP2 dysfunction: assessment of potential treatment options," Future Neurology, vol. 8, no. 1, pp. 21-28, 2013.

[189] A. Banerjee, E. Romero-Lorenzo, and M. Sur, "MeCP2: making sense of missense in Rett syndrome," Cell Research, vol. 23, pp. 1244-1246, 2013.

[190] K. N. McFarland, M. N. Huizenga, S. B. Darnell et al., "MeCP2: a novel Huntingtin interactor," Human Molecular Genetics, vol. 23, no. 4, pp. 1036-1044, 2014.

[191] B. Suter, D. Treadwell-Deering, H. Y. Zoghbi, D. G. Glaze, and J. L. Neul, "Brief report: MECP2 mutations in people without rett syndrome," Journal of Autism and Developmental Disorders, vol. 44, no. 3, pp. 703-711, 2014. 
[192] R. Bowser, "Race as a proxy for drug response: the dangers and challenges of ethnic drugs," De Paul Law Review, vol. 53, no. 3 , pp. 1111-1126, 2004.

[193] S. L. Chan, C. Suo, S. C. Lee, B. C. Goh, K. S. Chia, and Y. Y. Teo, "Translational aspects of genetic factors in the prediction of drug response variability: a case study of warfarin pharmacogenomics in a multi-ethnic cohort from Asia," Pharmacogenomics Journal, vol. 12, no. 4, pp. 312-318, 2012.

[194] D. E. Johnson, K. Park, and D. A. Smith, "Ethnic variation in drug response: Implications for the development and regulation of drugs," Current Opinion in Drug Discovery and Development, vol. 11, no. 1, pp. 29-31, 2008.

[195] J. M. Gorman, "Gender differences in depression and response to psychotropic medication," Gender Medicine, vol. 3, no. 2, pp. 93-109, 2006.

[196] S. Bano, S. Akhter, and M. I. Afridi, "Gender based response to fluoxetine hydrochloride medication in endogenous depression," Journal of the College of Physicians and Surgeons Pakistan, vol. 14, no. 3, pp. 161-165, 2004.

[197] A. R. Ferrari, R. Guerrini, G. Gatti, M. G. Alessandrì, P. Bonanni, and E. Perucca, "Influence of dosage, age, and comedication on plasma topiramate concentrations in children and adults with severe epilepsy and preliminary observations on correlations with clinical response," Therapeutic Drug Monitoring, vol. 25, no. 6, pp. 700-708, 2003.

[198] T. Q. Tran, C. Z. Grimes, D. Lai, C. L. Troisi, and L. Y. Hwang, "Effect of age and frequency of injections on immune response to hepatitis B vaccination in drug users," Vaccine, vol. 30, no. 2, pp. 342-349, 2012.

[199] V. Y. Martiny and M. A. Miteva, "Advances in molecular modeling of human cytochrome P450 polymorphism," Journal of Molecular Biology, vol. 425, pp. 3978-3992, 2013.

[200] M. E. Stauble, A. W. Moore, and L. J. Langman, "Hydrocodone in postoperative personalized pain management: pro-drug or drug?" Clinica Chimica Acta, vol. 429, pp. 26-29, 2014.

[201] K. Handa, I. Nakagome, N. Yamaotsu, H. Gouda, and S. Hirono, "In silico study on the inhibitory interaction of drugs with wild-type CYP2D6.1 and the natural variant CYP2D6.17," Drug Metabolism and Pharmacokinetics, vol. 29, no. 1, pp. 52-60, 2014.

[202] B. Moy, D. Tu, J. L. Pater et al., "Clinical outcomes of ethnic minority women in MA.17: a trial of letrozole after 5 years of tamoxifen in postmenopausal women with early stage breast cancer," Annals of Oncology, vol. 17, no. 11, pp. 1637-1643, 2006.

[203] M. Zhan, J. A. Flaws, L. Gallicchio, K. Tkaczuk, L. M. Lewis, and R. Royak-Schaler, "Profiles of tamoxifen-related side effects by race and smoking status in women with breast cancer," Cancer Detection and Prevention, vol. 31, no. 5, pp. 384-390, 2007.

[204] A. N. Tucker, K. A. Tkaczuk, L. M. Lewis, D. Tomic, C. K. Lim, and J. A. Flaws, "Polymorphisms in cytochrome P4503A5 (CYP3A5) may be associated with race and tumor characteristics, but not metabolism and side effects of tamoxifen in breast cancer patients," Cancer Letters, vol. 217, no. 1, pp. 61-72, 2005.

[205] P. C. Ng, S. S. Murray, S. Levy, and J. C. Venter, "An agenda for personalized medicine," Nature, vol. 461, no. 7265, pp. 724-726, 2009.

[206] Y. Bromberg, "Building a genome analysis pipeline to predict disease risk and prevent disease," Journal of Molecular Biology, vol. 425, no. 21, pp. 3993-4005, 2013.

[207] J. D. Momper and J. A. Wagner, “Therapeutic drug monitoring as a component of personalized medicine: applications in pediatric drug development," Clinical Pharmacology \& Therapeutics, vol. 95, pp. 138-140, 2014.
[208] S. J. Bielinski, J. E. Olson, J. Pathak, R. M. Weinshilboum, and L. Wang, "Preemptive genotyping for personalized medicine: design of the right drug, right dose, right time-using genomic data to individualize treatment protocol," Mayo Clinic Proceedings, vol. 89, pp. 25-33, 2014.

[209] W. Burke, S. Brown Trinidad, and N. A. Press, "Essential elements of personalized medicine," Urologic Oncology, vol. 32, no. 2, pp. 193-197, 2014.

[210] F. R. Vogenberg, C. I. Barash, and M. Pursel, "Personalized medicine: part 2: ethical, legal, and regulatory issues," Pharmacy and Therapeutics, vol. 35, pp. 624-642, 2010.

[211] L. S. Welch, K. Ringen, J. Dement et al., "Beryllium disease among construction trade workers at department of energy nuclear sites," American Journal of Industrial Medicine, vol. 56, no. 10, pp. 1125-1136, 2013.

[212] A. Kricker, B. K. Armstrong, A. J. McMichael, S. Madronich, and F. de Gruijl, "Skin cancer and ultraviolet," Nature, vol. 368, no. 6472 , p. 594, 1994.

[213] E. R. Park, J. M. Streck, I. F. Gareen et al., "A qualitative study of lung cancer risk perceptions and smoking beliefs among national lung screening trial participants," Nicotine \& Tobacco Research, vol. 16, pp. 166-173, 2014.

[214] B. S. McEwen and L. Getz, "Lifetime experiences, the brain and personalized medicine: an integrative perspective," Metabolism, vol. 62, supplement 1, pp. S20-S26, 2013.

[215] K. A. Mussatto, R. G. Hoffmann, G. M. Hoffman, J. S. Tweddell, and L. Bear, "Risk and prevalence of developmental delay in young children with congenital heart disease," Pediatrics, vol. 133, pp. e570-e577, 2014.

[216] A. R. Miller, "Lifetime care for patients with autism," CMAJ, vol. 182, no. 10, pp. 1079-1080, 2010.

[217] J. van der Leeuw, P. M. Ridker, Y. van der Graaf, and F. L. Visseren, "Personalized cardiovascular disease prevention by applying individualized prediction of treatment effects," European Heart Journal, vol. 35, no. 13, pp. 837-843, 2014.

[218] E. Faulkner, L. Annemans, L. Garrison et al., "Challenges in the development and reimbursement of personalized medicinepayer and manufacturer perspectives and implications for health economics and outcomes research: a report of the ISPOR personalized medicine special interest group," Value in Health, vol. 15, no. 8, pp. 1162-1171, 2012.

[219] L. Clarke, X. Zheng-Bradley, R. Smith et al., "The 1000 genomes project: data management and community access," Nature Methods, vol. 9, no. 5, pp. 459-462, 2012.

[220] G. R. Abecasis, D. Altshuler, A. Auton, L. D. Brooks, and R. M. Durbin, "A map of human genome variation from populationscale sequencing," Nature, vol. 467, pp. 1061-1073, 2010.

[221] T. A. de Beer, R. A. Laskowski, S. L. Parks et al., "Amino acid changes in disease-associated variants differ radically from variants observed in the 1000 genomes project dataset," PLOS Computational Biology, vol. 9, no. 12, Article ID e1003382, 2013. 

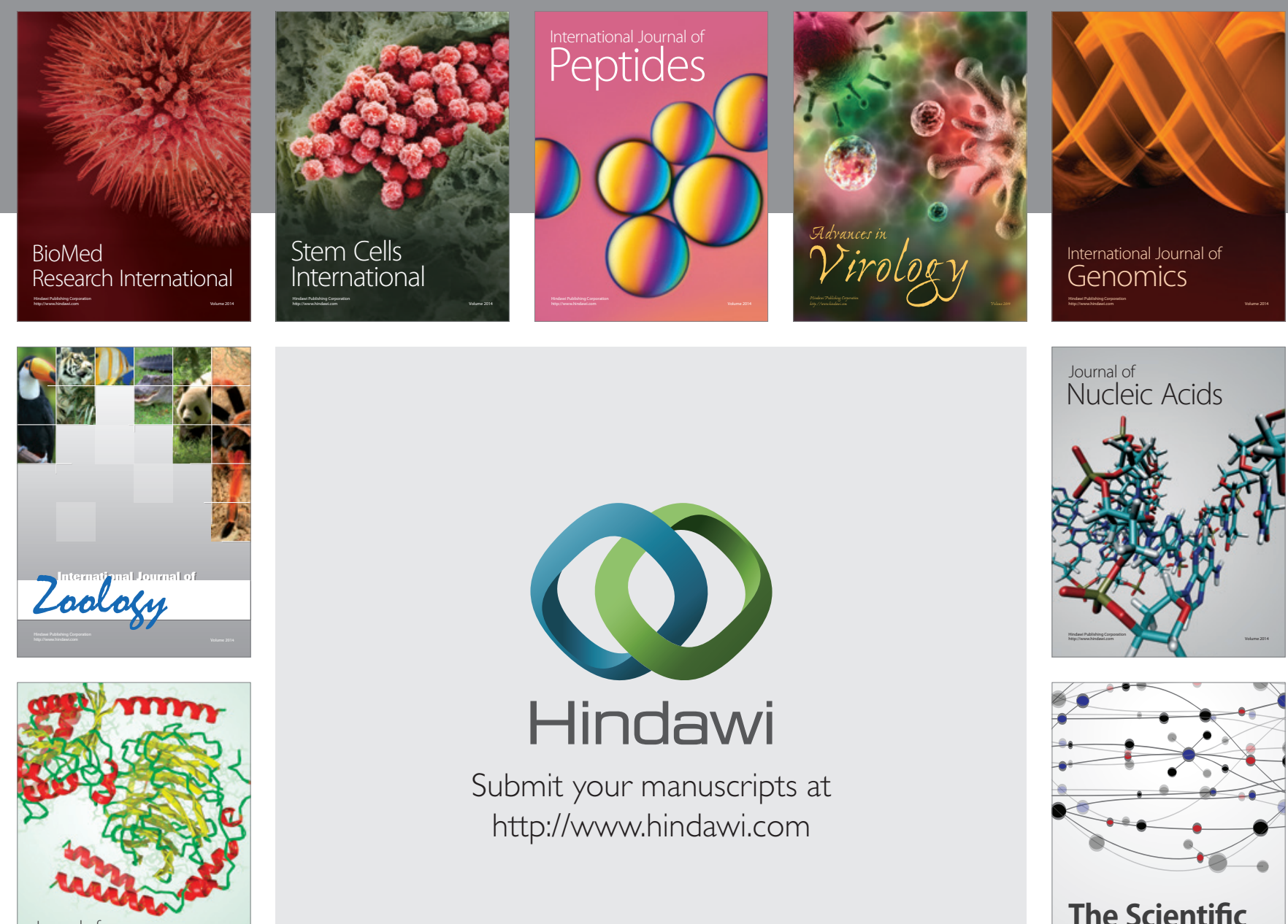

Submit your manuscripts at

http://www.hindawi.com

Journal of
Signal Transduction
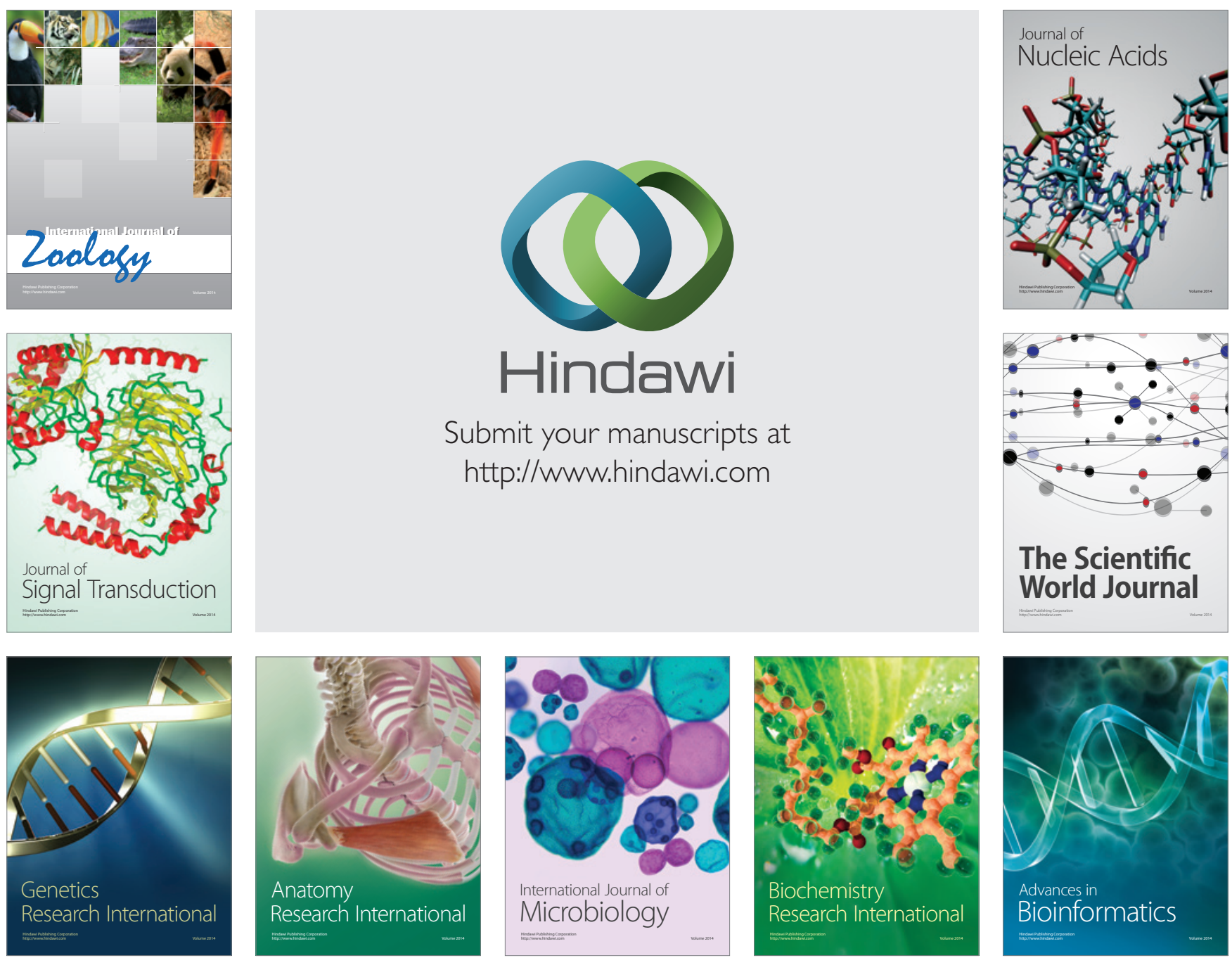

The Scientific World Journal
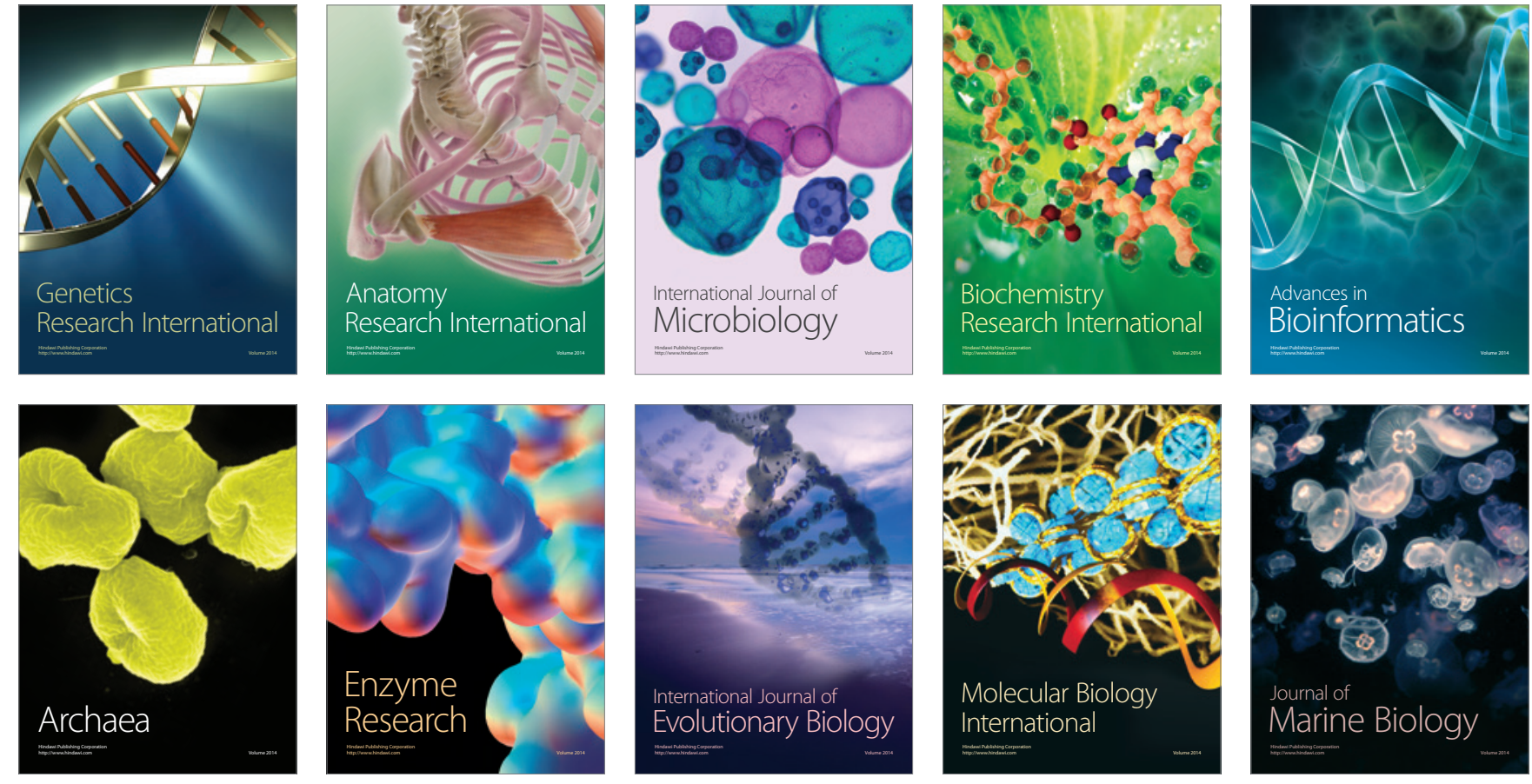